NBER WORKING PAPER SERIES

INERTIA, MARKET POWER, AND ADVERSE SELECTION IN HEALTH INSURANCE: EVIDENCE FROM THE ACA EXCHANGES

\author{
Evan Saltzman \\ Ashley Swanson \\ Daniel Polsky \\ Working Paper 29097 \\ http://www.nber.org/papers/w29097 \\ NATIONAL BUREAU OF ECONOMIC RESEARCH \\ 1050 Massachusetts Avenue \\ Cambridge, MA 02138 \\ July 2021
}

We are grateful to Matthew Grennan, Ian McCarthy, Melinda Pitts, Daniel Prinz, Amanda Starc, and Robert Town, and to audiences at Emory University and the Southeastern Health Economics Working Group, for helpful discussions and feedback. Sam Wunderly, Jett Pettus, and Sergio Andres Florez Orrego provided excellent research assistance. Daniel Polsky received consulting fees from Extend Health. The views expressed herein are those of the authors and do not necessarily reflect the views of the National Bureau of Economic Research.

NBER working papers are circulated for discussion and comment purposes. They have not been peer-reviewed or been subject to the review by the NBER Board of Directors that accompanies official NBER publications.

(C) 2021 by Evan Saltzman, Ashley Swanson, and Daniel Polsky. All rights reserved. Short sections of text, not to exceed two paragraphs, may be quoted without explicit permission provided that full credit, including $\odot$ notice, is given to the source. 
Inertia, Market Power, and Adverse Selection in Health Insurance: Evidence from the ACA

Exchanges

Evan Saltzman, Ashley Swanson, and Daniel Polsky

NBER Working Paper No. 29097

July 2021

JEL No. G22,I11,I13,L1

\begin{abstract}
We study how inertia interacts with market power and adverse selection in managed competition health insurance markets. We use consumer-level data to estimate a model of the California ACA exchange, in which four firms dominate the market and risk adjustment is in place to manage selection. We estimate high inertia costs, equal to $44 \%$ of average premiums. Although eliminating inertia exacerbates adverse selection, it significantly reduces market power such that average premiums decrease $13.2 \%$ and annual per-capita welfare increases $\$ 902$. These effects are substantially smaller in settings without market power and/or risk adjustment. Moreover, converting the ACA's premium-linked subsidies to vouchers mitigates the impact of inertia by reducing market power, whereas reducing high consumer churn in the ACA exchanges increases the impact of inertia by enhancing market power. The impact of inertia is not sensitive to provider network generosity, despite greater consumer attachment to plans with more differentiated provider networks.

Evan Saltzman

Emory University

Department of Economics

1602 Fishburne Drive

Rich Memorial Building, Room 306B

Atlanta, GA 30332

evan.saltzman@emory.edu

Ashley Swanson

Graduate School of Business

Columbia University

3022 Broadway, Uris Hall 621

New York, NY 10027

and NBER

ats2180@gsb.columbia.edu

Daniel Polsky

Carey Business School

Department of Health Policy and Management

Bloomberg School of Public Health

Johns Hopkins University

624 N. Broadway, Room 661

Baltimore, MD 21205

polsky@jhu.edu
\end{abstract}


Managed competition is increasingly common in U.S. health insurance markets, such as the Medicare Advantage and Medicare Part D programs for seniors and the Affordable Care Act (ACA) individual health insurance exchanges (HIXs) (Einav and Levin, 2015). ${ }^{1}$ Insurance markets with managed competition aim to leverage the advantages of competition among private firms by promoting consumer choice while limiting firm incentives to engage in risk selection and offer substandard benefit packages (Enthoven, 1993). Common elements include consumer choice among qualifying plans, regulations that set baseline benefits, and policies that promote competition and limit incentives for risk selection. The efficient functioning of these markets is important not only for consumer welfare, but also for the prudent allocation of significant government expenditures. Successful implementation depends on the interaction of three critical and interconnected factors: the incentive and ability of consumers to choose high-value options, the participation and competition of firms, and policies in place to manage adverse selection.

We explore the interaction of these three factors in the ACA exchanges. Choice and information frictions can undermine the market forces underlying managed competition's presumed advantages by eroding insurers' incentives to issue high-value options. We examine this issue by focusing on the role of inertia, the persistence of health plan choices over time despite changes in premiums and health plan offerings. Inertia could reduce consumer welfare by inducing consumers to remain in suboptimal plans and by reducing insurers' incentives to lower premiums. ${ }^{2}$ However, inertia may also mitigate the effects of adverse selection (Handel, 2013). The balance of these forces depends on the extent of competition (Polyakova, 2016) and on policies in place to manage risk selection, such as risk adjustment (Geruso et al., 2019; Mahoney and Weyl, 2017).

We analyze the premium, enrollment, and welfare impacts of inertia in the ACA setting. The ACA's architects designed the exchanges with the intent to encourage frictionless consumer choice and robust insurer competition. ${ }^{3}$ We provide new evidence on the presence and magnitude of choice

\footnotetext{
${ }^{1}$ Although managed competition is relatively new in the U.S., health insurance systems in the Netherlands, Germany, and Switzerland have relied on managed competition for decades.

${ }^{2}$ Researchers have documented the presence and magnitude of inertia in the employer group setting (Handel, 2013), in the Medicare Part D market (Ericson, 2014; Fleitas, 2017; Ho et al., 2017; Polyakova, 2016), in Medicare Advantage (Miller, 2019), and in the ACA exchanges (Drake et al., 2021). These papers, and our own, lie at the intersection of broader literatures on choice frictions as a source of welfare loss and market power in health insurance (Abaluck and Adams, 2018; Abaluck and Gruber, 2011, 2016; Aizawa and Kim, 2018; Cebul et al., 2011; Bhargava et al., 2017; Ketcham et al., 2015; Kling et al., 2012), and on the effects of inertia on competition in markets other than health insurance (Dube et al., 2009; Farrell and Klemperer, 2007; Hortacsu et al., 2017; Luco, 2019).

${ }^{3}$ To facilitate choice, they standardized key plan features, allowed consumers to shop and enroll online, and provided access to choice assistance from professional navigators. To encourage firm participation and limit adverse selection, ACA policies introduced risk corridors, reinsurance, and risk adjustment, and mandated and subsidized insurance purchase. In practice, several of these design elements have disappeared or been eroded in the seven years since the exchanges opened.
} 
frictions in this environment, and on how important features of the ACA exchange mediate their effects on social welfare. In doing so, we contribute to a burgeoning literature on the early successes and failures of the new insurance marketplaces established by the ACA (Abraham et al., 2017; Sen and DeLeire, 2018; Diamond et al., 2021; Drake, 2019; Panhans, 2019; Polsky et al., 2016; Tebaldi, 2020), as well as the broader empirical literature on managed competition markets such as Medicare Part D (Decarolis et al., 2020), Medicare Advantage (Curto et al., 2020; Miller et al., 2019), and the pre-ACA Massachusetts exchange (Ericson and Starc, 2015, 2016; Geruso et al., 2019; Hackmann et al., 2015; Shepard, 2016).

To study the impact of inertia in the ACA exchanges, we estimate a model of consumer plan choice and insurer pricing. Our model endogenizes consumer choices, premiums, plan risk, and claims. The model explicitly allows for both moral hazard and adverse selection and incorporates key ACA policies such as risk adjustment and premium subsidies. Our approach is similar to those in Starc (2014) and Tebaldi (2020) and builds directly on the model in Saltzman (2021).

We estimate our model using consumer-level administrative data from the ACA exchange in California. Our data contain nearly ten million consumer plan choices across a variety of local insurance market settings between 2014 and 2018, the first five years of the exchange. The California ACA exchange is an important market for understanding the individual exchanges because it accounts for $13 \%$ of nationwide enrollment (Kaiser Family Foundation, 2020). It is also a useful market for exploring inertia because plan financial characteristics are standardized, limiting the number of plan attributes consumers need to compare. Descriptive evidence suggests inertia is high. Nearly $80 \%$ of renewing enrollees remained in the same plan, $91 \%$ chose a plan in the same metal tier, and $87 \%$ stayed with the same insurer. New enrollees paid lower premiums than renewing enrollees and firms with higher market shares raised premiums more in the subsequent year.

To quantify the equilibrium effects of inertia, we estimate a structural model of the California ACA exchange. We address potential endogeneity of plan premiums by exploiting variation created by exogenous ACA regulations, including the phase-in of the individual mandate penalty and the time-varying kinks in the ACA penalty and subsidy formulas. We identify inertia by leveraging two key features of the ACA setting captured by our data: (1) every consumer in our model makes at least one "active" decision, either when the exchanges opened in 2014 or in a subsequent year; and (2) some consumers make additional active decisions if their previous plans cease being offered.

We use our estimated model to simulate the impact of inertia under observed and alternative market conduct and policy scenarios. We make three primary contributions to the literature: (1) we estimate the magnitude of inertia and how its elimination would impact equilibrium premiums, plan choices, and welfare in the observed ACA setting; (2) we document how and why the impact 
of eliminating inertia would change if firm market power and/or the risk adjustment policy in place to manage adverse selection were to be removed; and (3) we provide insight into how three policydriven features of managed competition in insurance markets, including the design of premium subsidies, consumer churn between markets, and provider network generosity, interact with inertia.

We find that inertia, measured as the annual cost of switching to a new plan, is $\$ 2,324$ for the average consumer or approximately $44 \%$ of the average premium. Higher-income consumers and adults over age 55 have switching costs of about $\$ 3,700$, whereas young adults between ages 18 and 34 have switching costs of about $\$ 1,500$. We also find lower inertia in Asian and Hispanic households and higher inertia in non-Hispanic White households. While these estimated switching costs are quite large, they are consistent with previous estimates in the literature (Drake et al., 2021; Handel, 2013; Polyakova, 2016).

Next, we use the estimated model to simulate the impact of inertia under alternative scenarios. The switching frictions underlying inertia may include time costs of comparing complex features of alternative plans and hassle costs associated with completing paperwork and changing providers. We simulate setting switching costs to zero ${ }^{4}$ and find average premiums would decrease by $13.2 \%$. Annual per-capita social welfare would increase by $\$ 902$ and annual total social welfare would increase by $\$ 2.13$ billion. Our baseline welfare analysis follows the literature in assuming that revealed preference can be used to calculate consumer surplus, and that inertia impacts choices but not welfare. When inertia is eliminated, some consumers choose less generous coverage (2\%) and others forgo insurance entirely (3\%); substantial errors in consumers' valuation of insurance (Abaluck et al., 2021) would amplify the welfare losses due to drops in enrollment. Our qualitative conclusions are largely robust to whether inertia is considered a choice error or a true welfarerelevant switching cost: the welfare effect of eliminating inertia remains positive provided no more than $80 \%$ of inertia represents a true switching cost.

The impact of inertia is substantially smaller when firm market power and/or risk adjustment are removed. If firms price at average cost, eliminating inertia would result in only $0.9 \%$ lower average premiums and a $\$ 547$ increase in annual per-capita social welfare. This result demonstrates how firms exploit inertia as a source of market power, as previously explored by Ho et al. (2017) and Polyakova (2016). ${ }^{5}$ Without risk adjustment in place to mitigate the effects of selection, eliminating inertia would result in $10.9 \%$ lower average premiums and a $\$ 658$ increase in annual

\footnotetext{
${ }^{4}$ In reality, there is likely no single intervention that would eliminate inertia, but several policies may reduce it, including alerts regarding product characteristics, information provision, and modified defaults. See, e.g., Domurat et al. (2021) and Kling et al. (2012).

${ }^{5}$ Our model does not incorporate dynamic firm pricing in response to consumer inertia (Dube et al., 2009; Ericson, 2014; Fleitas, 2017; Miller, 2019). We consider this an important area for future work on the ACA setting.
} 
per-capita social welfare. The premium decrease is smaller than in the ACA setting because removing risk adjustment leads to premium dispersion (i.e., less generous plans become cheaper and more generous plans become more expensive) and significant shifts in enrollment from more generous plans to less generous plans. Eliminating inertia without risk adjustment in place therefore results in smaller incremental premium decreases and enrollment shifts. In the absence of both market power and risk adjustment, eliminating inertia would decrease average premiums by $2.9 \%$ and increase annual per-capita social welfare by only $\$ 250$. These results complement prior work on the interactions between risk adjustment and market power (Mahoney and Weyl, 2017).

Our simulation results also demonstrate how three policy-driven features of the ACA environment interact with inertia. First, the ACA exchanges feature premium subsidies that are linked to premiums. Price-linked subsidies reduce price competition (Einav et al., 2019; Jaffe and Shepard, 2020; Polyakova, 2016; Tebaldi, 2020) and hence exacerbate market power from inertia. We simulate the effect of inertia under a voucher or fixed government subsidy and find a significantly smaller impact than under price-linked subsidies. Eliminating inertia with fixed subsidies results in a $8.9 \%$ decrease in average premiums and a $\$ 532$ increase in annual per-capita social welfare. Another prominent feature of the ACA setting that interacts with inertia is consumer churn into and out of the market (Diamond et al., 2021). In our data, 26\% of enrollees exit the ACA marketplace each year due to exogenous reasons such as receiving an offer for employer-sponsored insurance or becoming eligible for Medicaid. In contrast to price-linked subsidies, high churn mitigates the effect of inertia on firms' market power. We simulate the elimination of inertia without churn in the market and find a larger impact than with churn. Average premiums would decrease by $16.8 \%$ and annual per-capita social welfare would increase by $\$ 966$. Finally, we study whether the impact of inertia is sensitive to provider network generosity. We quantify the impacts of network breadth and network inclusivity (Graves et al., 2020), the degree to which the providers in a plan's network are shared with other plans in the market, on inertial behavior. This analysis complements prior work that studies the mechanisms underlying inertia in insurance and other settings (Abaluck and Adams, 2018; Brot-Goldberg et al., 2021; Drake et al., 2021; Heiss et al., 2016; Hortacsu et al., 2017; Luco, 2019). We find network inclusivity slightly reduces inertia, suggesting that provider preference may keep consumers in their plans. However, eliminating only the part of inertia not driven by network inclusivity yields similar estimates as in our main results.

Taken together, our results present new evidence on how inertia, competition, and adverse selection interact in an important health insurance marketplace. Policies targeting inertia, such as signup simplification and plan standardization, may be most effective in markets such as the ACA exchanges where firms have market power and adverse selection is managed with measures such 
as risk adjustment. Our paper also clarifies how subsidy design, consumer churn, and provider network regulation may mediate the effects of inertia. Switching to a fixed subsidy design would mitigate the effects of inertia because it would reduce firm market power. Conversely, policies mitigating consumer churn such as expanding subsidy eligibility to those with access to employersponsored insurance or implementing the ACA's Basic Health Program (BHP) could exacerbate the effects of inertia by enhancing firm market power over inertial enrollees. Lastly, our results suggest that regulations regarding provider network breadth would not substantially change the impact of inertia.

This paper is organized as follows. Section 1 describes the data and provides descriptive evidence of inertia. Section 2 presents our empirical demand model and estimates. Section 3 simulates the impact of inertia in the ACA exchanges on premiums, enrollment, claims, and welfare. Section 4 concludes.

\section{Data and Setting}

A central component of the ACA was the establishment in 2014 of state-based and federallyfacilitated exchanges for non-group health insurance, in which eligible consumers choose among qualified health plans and purchase plans with federal subsidies. In this paper, we analyze enrollment data and insurer rate filings from the California ACA exchange from 2014-2018. ${ }^{6}$ The enrollment data contain plan choices for each enrollee-year, as well as enrollee demographic characteristics such as age, geographic location, and income. The insurer rate filings contain plan-yearmarket-level information on administrative costs, enrollee claims, risk adjustment transfers, and reinsurance. The following two subsections provide more detail on each dataset and descriptive evidence of inertia.

\subsection{Premiums and Enrollment}

We analyze consumer-level enrollment data from the California ACA exchange for the 2014 through 2018 plan years. Table 1 summarizes enrollee choices and characteristics. Any citizen or legal resident can enroll in an ACA exchange plan. However, in practice, the rules governing the availability of subsidies imply that the exchanges primarily serve individuals without access to affordable employer- or government-sponsored insurance. We refer to these individuals as "exchangeeligible." These eligibility rules were put into place to limit the cost of the ACA and avoid crowd-out

\footnotetext{
${ }^{6}$ We rely on the same data as in Saltzman (2021).
} 
of other sources of insurance coverage, including employer- or government-sponsored insurance. A significant consequence of these restrictions is high consumer churn, which we investigate below. The ACA contained a provision for states to establish a Basic Health Program that would reduce churn between Medicaid and the ACA exchanges, but only New York and Minnesota have implemented a BHP program as of $2021 .^{7}$

Appendix A details how we construct the exchange-eligible population. Briefly, we begin with the set of consumers who ever enrolled in a California ACA plan. For years when the consumer is not enrolled in an ACA plan, we impute whether the consumer was exchange-eligible, given their age, gender, race, income, and household size. This imputation exercise draws on a prediction model trained on observed coverage status transitions (i.e., ACA exchange insurance, employersponsored insurance, government-sponsored insurance, and no insurance) in individual-level panel data from the U.S. Census Bureau's Survey of Income and Program Participation (SIPP) (U.S. Census Bureau, 2019).

Approximately two-thirds of eligible consumers chose an exchange plan in our sample. Enrollment increased steadily from $62 \%$ to $70 \%$ of eligible consumers between 2014 and 2018. The ACA mandates that most consumers purchase coverage or pay a penalty; exceptions are made for people with valid reasons, such as having income below the threshold for filing taxes or lacking access to a plan that costs less than $8 \%$ of household income. In 2014 , the penalty was $\$ 95$ or $1 \%$ of income, whichever was larger. The penalty increased each year until 2016, when it was $\$ 695$ or $2.5 \%$ of income, whichever was larger. In 2019, the penalty was set to zero following passage of the Tax Cuts and Jobs Act of 2017.

Approximately 52\% of enrollees were female, $39 \%$ were non-Hispanic white, and 50\% were over age 45. Exchange enrollees tended to have relatively low incomes: half of enrollees in our sample had incomes below $200 \%$ of the federal poverty level (FPL), and $90 \%$ had incomes below $400 \%$ of the FPL. Nearly $90 \%$ of enrollees received premium subsidies. ${ }^{8}$ As we discuss in more detail in the next section, premium subsidies are linked to premiums in the silver tier and shield consumers from premium volatility.

\footnotetext{
${ }^{7}$ The BHP program covers consumers with incomes between the $138 \%$ of FPL Medicaid threshold to $200 \%$ of FPL in a Medicaid-type plan with lower premiums and cost sharing than an ACA exchange plan. The program reduces churn for people with income close to the $138 \%$ of FPL Medicaid threshold because transitions between Medicaid and the BHP are relatively seamless. Although churn may increase for consumers with income around $200 \%$ of FPL, income fluctuations are generally more prevalent in lower-income populations.

${ }^{8}$ Premium subsidies are available to citizens and legal residents with income between $100 \%$ and $400 \%$ of FPL who do not qualify for Medicaid and do not have an affordable offer of insurance from their employer. Most California consumers who have income under 138\% of FPL qualify for Medicaid. An employer-sponsored insurance plan was considered affordable in 2014 if the employee's contribution to the plan was below $9.5 \%$ of household income.
} 
Table 1: Plan Choices and Enrollee Demographics

\begin{tabular}{|c|c|c|c|c|c|c|}
\hline & 2014 & 2015 & 2016 & 2017 & 2018 & Overall \\
\hline Market Size & $2,197,669$ & $2,420,764$ & $2,461,389$ & $2,444,685$ & $2,429,209$ & $11,953,716$ \\
\hline Total Enrollment & $1,362,316$ & $1,639,923$ & $1,702,160$ & $1,697,074$ & $1,710,469$ & $8,111,942$ \\
\hline \multicolumn{7}{|l|}{ Metals } \\
\hline Catastrophic & $1.0 \%$ & $0.8 \%$ & $1.0 \%$ & $1.1 \%$ & $1.2 \%$ & $1.0 \%$ \\
\hline Bronze & $23.7 \%$ & $25.2 \%$ & $26.3 \%$ & $26.7 \%$ & $28.9 \%$ & $26.3 \%$ \\
\hline Silver & $63.9 \%$ & $63.8 \%$ & $63.7 \%$ & $63.8 \%$ & $54.7 \%$ & $61.9 \%$ \\
\hline Gold & $6.0 \%$ & $5.5 \%$ & $5.1 \%$ & $5.2 \%$ & $11.2 \%$ & $6.6 \%$ \\
\hline Platinum & $5.4 \%$ & $4.7 \%$ & $3.9 \%$ & $3.2 \%$ & $3.9 \%$ & $4.2 \%$ \\
\hline \multicolumn{7}{|l|}{ Insurers } \\
\hline Anthem & $29.7 \%$ & $27.9 \%$ & $25.1 \%$ & $17.5 \%$ & $4.7 \%$ & $20.6 \%$ \\
\hline Blue Shield & $27.8 \%$ & $25.9 \%$ & $28.9 \%$ & $25.5 \%$ & $31.4 \%$ & $27.9 \%$ \\
\hline Health Net & $19.4 \%$ & $16.6 \%$ & $11.9 \%$ & $10.5 \%$ & $14.0 \%$ & $14.3 \%$ \\
\hline Kaiser & $17.7 \%$ & $24.1 \%$ & $24.0 \%$ & $28.9 \%$ & $34.1 \%$ & $26.1 \%$ \\
\hline Other & $5.5 \%$ & $5.4 \%$ & $10.1 \%$ & $17.6 \%$ & $15.7 \%$ & $11.1 \%$ \\
\hline \multicolumn{7}{|l|}{ Network Type } \\
\hline HMO & $43.1 \%$ & $48.3 \%$ & $46.5 \%$ & $58.4 \%$ & $64.3 \%$ & $52.5 \%$ \\
\hline PPO & $56.9 \%$ & $51.7 \%$ & $53.5 \%$ & $41.6 \%$ & $35.7 \%$ & $47.5 \%$ \\
\hline \multicolumn{7}{|l|}{ Income } \\
\hline $138 \%$ FPL or less & $4.7 \%$ & $3.5 \%$ & $3.3 \%$ & $4.0 \%$ & $4.0 \%$ & $3.8 \%$ \\
\hline $138 \%$ FPL to $150 \%$ FPL & $14.1 \%$ & $14.3 \%$ & $14.6 \%$ & $14.7 \%$ & $14.4 \%$ & $14.4 \%$ \\
\hline $150 \%$ FPL to $200 \%$ FPL & $32.8 \%$ & $32.8 \%$ & $31.9 \%$ & $30.3 \%$ & $28.8 \%$ & $31.3 \%$ \\
\hline $200 \%$ FPL to $250 \%$ FPL & $16.8 \%$ & $16.7 \%$ & $16.3 \%$ & $16.3 \%$ & $16.7 \%$ & $16.6 \%$ \\
\hline $250 \%$ FPL to $400 \%$ FPL & $22.4 \%$ & $23.4 \%$ & $23.6 \%$ & $23.6 \%$ & $25.8 \%$ & $23.8 \%$ \\
\hline $400 \%$ FPL or greater & $9.3 \%$ & $9.3 \%$ & $10.3 \%$ & $11.0 \%$ & $10.3 \%$ & $10.1 \%$ \\
\hline \multicolumn{7}{|l|}{ Subsidy Status } \\
\hline Subsidized & $89.6 \%$ & $88.8 \%$ & $87.5 \%$ & $86.5 \%$ & $87.3 \%$ & $87.9 \%$ \\
\hline Unsubsidized & $10.4 \%$ & $11.2 \%$ & $12.5 \%$ & $13.5 \%$ & $12.7 \%$ & $12.1 \%$ \\
\hline \multicolumn{7}{|l|}{ Age } \\
\hline $0-17$ & $5.7 \%$ & $6.0 \%$ & $6.2 \%$ & $6.7 \%$ & $7.3 \%$ & $6.4 \%$ \\
\hline $18-25$ & $11.1 \%$ & $11.3 \%$ & $11.1 \%$ & $10.7 \%$ & $10.5 \%$ & $10.9 \%$ \\
\hline $26-34$ & $16.3 \%$ & $16.9 \%$ & $17.4 \%$ & $17.6 \%$ & $17.7 \%$ & $17.2 \%$ \\
\hline $35-44$ & $16.6 \%$ & $15.9 \%$ & $15.3 \%$ & $15.1 \%$ & $15.2 \%$ & $15.6 \%$ \\
\hline $45-54$ & $24.4 \%$ & $23.5 \%$ & $22.8 \%$ & $22.2 \%$ & $21.4 \%$ & $22.8 \%$ \\
\hline $55+$ & $25.8 \%$ & $26.3 \%$ & $27.2 \%$ & $27.8 \%$ & $27.9 \%$ & $27.1 \%$ \\
\hline \multicolumn{7}{|l|}{ Gender } \\
\hline Female & $52.6 \%$ & $52.2 \%$ & $51.9 \%$ & $52.2 \%$ & $52.5 \%$ & $52.3 \%$ \\
\hline Male & $47.4 \%$ & $47.8 \%$ & $48.1 \%$ & $47.8 \%$ & $47.5 \%$ & $47.7 \%$ \\
\hline \multicolumn{7}{|l|}{ Race } \\
\hline Asian & $22.8 \%$ & $21.8 \%$ & $22.0 \%$ & $22.6 \%$ & $23.0 \%$ & $22.4 \%$ \\
\hline Black/African American & $2.7 \%$ & $2.5 \%$ & $2.4 \%$ & $2.4 \%$ & $2.4 \%$ & $2.5 \%$ \\
\hline Hispanic & $27.5 \%$ & $28.2 \%$ & $28.0 \%$ & $28.3 \%$ & $28.4 \%$ & $28.1 \%$ \\
\hline Non-Hispanic White & $39.4 \%$ & $39.5 \%$ & $39.6 \%$ & $38.5 \%$ & $37.1 \%$ & $38.8 \%$ \\
\hline Other Race & $7.7 \%$ & $7.9 \%$ & $7.9 \%$ & $8.2 \%$ & $9.1 \%$ & $8.2 \%$ \\
\hline
\end{tabular}

Table summarizes enrollee plan choices and demographic distributions using California administrative data. The total market size is imputed using data from the SIPP as discussed in Appendix A. 
Like many U.S. health insurance markets, the ACA exchanges are concentrated (Dafny, 2015). In our sample, four large insurers-Anthem Blue Cross, Blue Shield of California, Health Net, and Kaiser-covered $89 \%$ of exchange enrollees. Those insurers had dominant positions throughout our sample, with one exception: Anthem's market share declined sharply after it exited all but 3 of the 19 California markets in 2018. The collective market share of the 9 small regional insurers increased from $5 \%$ in 2014 to $16 \%$ in $2018 .^{9}$

Exchange plans are grouped into four "metal" tiers with differing levels of actuarial value (AV): bronze (60\% AV), silver (70\% AV), gold (80\% AV), and platinum (90\% AV). The plan AV defines the percentage of total covered costs for which a plan pays. For example, enrollees in a plan with $70 \%$ actuarial value are responsible for $30 \%$ of the costs of all covered benefits they incur, on average. Over $60 \%$ of enrollees chose a silver plan because access to cost sharing reductions (CSRs) that reduce copays, coinsurance, and deductibles requires enrollment in a silver plan. CSRs increase the silver plan AV from $70 \%$ to $73 \%, 87 \%$, or $94 \%$, depending on the consumer's income. CSRs are not available to households with income exceeding $250 \%$ of FPL. Roughly two-thirds of consumers in our data can access CSRs. In many states, insurers have flexibility in how they design plans' costsharing features to achieve a given AV. However, the California exchange has standardized all plans in the same metal tier to have identical cost sharing. ${ }^{10}$ In addition to the "metal" plans, catastrophic plans with much higher deductibles are available to individuals under age 30, but represented only $1 \%$ of enrollment share in our sample. California exchange consumers had an average of 27 plans offered by 4.75 insurers to choose from, though there was considerable heterogeneity in choice set sizes. Los Angeles County residents could choose from as many as 45 plans offered by 7 insurers, whereas residents in rural areas of Northern California could choose from as few as 5 plans offered by a single insurer.

Figure 1 summarizes annual enrollment transitions across metal tiers and insurers. Two important features of the California exchange in 2014-2018 stand out. First, consumer churn was substantial. Approximately 35\% of enrollees in year $t$ were not enrolled in year $t+1$. Transitions out of enrollment could be due to "Ineligibility" (approximately 26\% of enrollees lost exchange eligibility due to exogenous factors, such as a change in labor market status or Medicaid eligibility), or to "Uninsurance" (approximately 9\% of enrollees remained eligible, but dropped coverage for other reasons). This phenomenon was relatively stable across metal tiers and insurers, though consumers were most likely to drop coverage if they were previously enrolled in a bronze plan. Second, plan

\footnotetext{
${ }^{9}$ These firms were Chinese Community Health Plan, Contra Costa, L.A. Care Health Plan, Molina Healthcare, Oscar, Sharp Health Plan, United Healthcare, Valley Health Plan, and Western Health Advantage.

${ }^{10}$ The 2019 benefit design is available at https://www.coveredca.com/PDFs/2019-Health-Benefits-table.pdf
} 
switching was relatively rare despite highly volatile premiums during our study timeframe. Among consumers that renewed coverage in our sample, approximately $79 \%$ chose last year's plan, $91 \%$ chose a plan from the same metal tier as last year's plan, and $87 \%$ chose a plan from the same insurer as last year's plan. Switching from Anthem to Blue Shield was slightly more common because Anthem exited most California markets in 2018 and many previous Anthem enrollees subsequently opted into Blue Shield. This high degree of inertia may reflect the role of defaults. At the end of each plan year, current enrollees are sent a renewal notice. Those who do not actively change plans are automatically enrolled into their current plans for the next plan year. In sum, the low levels of switching between plans suggest that inertia was high, but high consumer churn into and out of the market may have muted some of the effects of inertia.

Table 2 summarizes average premium spending by year and enrollment status. The average household paid a subsidized monthly premium of $\$ 136$, which is approximately $31 \%$ of the average unsubsidized premium of $\$ 434$. Households who switched plans paid $\$ 134$ on average and consumers choosing a plan for the first time paid $\$ 130$ on average. Although this descriptive evidence does not adjust for differences in the premiums available to incumbent enrollees and to new enrollees and switchers, it suggests consumers may benefit from annually reviewing their plan options. Another notable feature of the data is that unsubsidized premiums increased sharply in 2018, largely as a result of the Trump Administration's decision to halt government funding of CSRs. Because insurers were still legally required to provide CSRs even after direct government funding was eliminated, they covered expenses through higher premiums. Many states (including California) responded by promoting the "silver loading" strategy, which encouraged insurers to only increase silver plan premiums to cover the cost of having to fund CSRs. Because premium subsidies are linked to silver plan premiums (see discussion of equation (2) below), consumers received larger premium subsidies under this strategy and paradoxically paid lower subsidized premiums in 2018.

Firms may exploit consumer inertia by more aggressively increasing premiums on plans with greater market share. To understand whether firms engage in this behavior, Table 3 presents the results of descriptive regressions of yearly (percentage) premium changes ( $t$ to $t+1)$ on lagged (year $t$ ) market share, controlling for plan generosity using the plan's actuarial value, the plan's risk score, an HMO dummy, and firm and market fixed effects. The first column indicates that a 10 percentage point increase in lagged plan market share is associated with an additional 1 percentage point increase in the year-to-year premium growth rate. This association could be driven by different cost trends among plans with greater enrollment, or by different cost trends in relatively concentrated markets. The third column sheds light on these potential mechanisms by including firm and market fixed effects, and indicates a strikingly similar pattern: a 10 percentage point in- 
Figure 1: Annual Enrollee Plan Transitions by Metal and Insurer

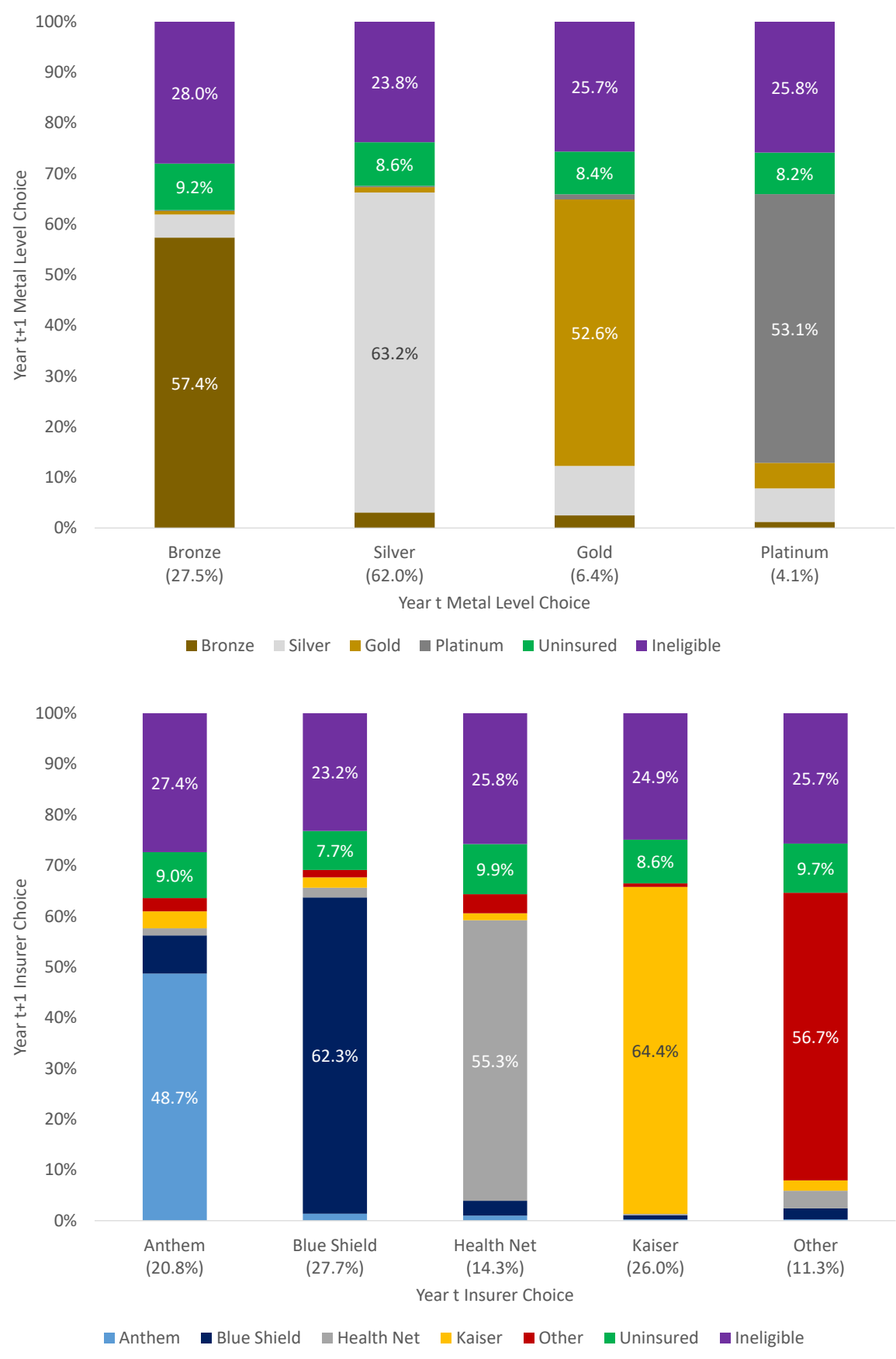

Figure reports enrollee transitions between plan years by metal tier (top panel) and insurer (bottom panel). Each bar shows the share of enrollees with the insurance status in year $t$, indicated on the categorical horizontal axis, who transition to the indicated insurance status in year $t+1$. In addition to choosing an exchange plan, consumers can be either uninsured, but eligible for the exchange, or ineligible for the exchange. For the sake of brevity, we combine bronze and catastrophic enrollment and label it "bronze"; this has little material impact, as only $1 \%$ of sample enrollees chose catastrophic plans. 
Table 2: Average Premium Spending By Year and Enrollment Status

\begin{tabular}{|c|c|c|c|c|c|c|}
\hline & \multicolumn{3}{|c|}{ Subsidized Premiums } & \multicolumn{3}{|c|}{ Unsubsidized Premiums } \\
\hline & All & New & Switchers & All & New & Switchers \\
\hline \multicolumn{7}{|c|}{ Average Premium } \\
\hline 2014 & $\$ 117$ & $\$ 117$ & & $\$ 379$ & $\$ 379$ & \\
\hline 2015 & $\$ 125$ & $\$ 124$ & $\$ 128$ & $\$ 392$ & $\$ 364$ & $\$ 398$ \\
\hline 2016 & $\$ 136$ & $\$ 133$ & $\$ 127$ & $\$ 405$ & $\$ 365$ & $\$ 392$ \\
\hline 2017 & $\$ 154$ & $\$ 148$ & $\$ 142$ & $\$ 447$ & $\$ 395$ & $\$ 445$ \\
\hline 2018 & $\$ 145$ & $\$ 146$ & $\$ 133$ & $\$ 535$ & $\$ 474$ & $\$ 539$ \\
\hline Overall & $\$ 136$ & $\$ 130$ & $\$ 134$ & $\$ 434$ & $\$ 390$ & $\$ 463$ \\
\hline
\end{tabular}

Table reports the enrollment-weighted average premium paid by California households, with and without premium subsidies. Table compares average premiums for all enrollees, enrollees joining the exchange for the first time, and consumers choosing a new plan.

crease in lagged plan market share is associated with an additional 1.3 percentage point increase in the year-to-year premium growth rate. This is consistent with inertia being a significant source of firm market power.

Table 3: Effect of Plan Market Share on Percentage Premium Increase

\begin{tabular}{lccc}
\hline \hline & $(1)$ & $(2)$ & $(3)$ \\
\hline Firm fixed effects & & $\checkmark$ & $\checkmark$ \\
Market fixed effects & & & $\checkmark$ \\
\hline Lagged Market Share & $0.099^{* * *}$ & $0.135^{* * *}$ & $0.135^{* * *}$ \\
& $(0.034)$ & $(0.034)$ & $(0.034)$ \\
Risk Score & $0.017^{* *}$ & $0.017^{* *}$ & $0.018^{* * *}$ \\
& $(0.008)$ & $(0.007)$ & $(0.007)$ \\
HMO & $-0.046^{* * *}$ & $-0.013^{*}$ & -0.010 \\
& $(0.004)$ & $(0.007)$ & $(0.007)$ \\
AV & 0.037 & 0.019 & 0.014 \\
& $(0.045)$ & $(0.038)$ & $(0.038)$ \\
\hline Observations & 1,326 & 1,326 & 1,326 \\
\hline
\end{tabular}

Notes: Robust standard errors are in parentheses $\left({ }^{*}\right.$ indicates statistical significance at the $10 \%$ level, ${ }^{* *}$ at the $5 \%$ level, and ${ }^{* * *}$ at the $1 \%$ level). Table displays the results of regressing the plan premium increase between years $t$ and $t+1$, in percentage terms, on the plan's market share in year $t$ and a set of controls. Observations are at the plan-year-market level. 


\subsection{Claims and Risk Adjustment}

We also use insurer rate filings from California's Department of Managed Care to obtain financial information on medical claims, reinsurance ${ }^{11}$, and risk adjustment (Department of Managed Health Care, 2016). For each of these financial variables, we observe the average (or per-member permonth) amount and total amount for each plan sold in each year and market. The rate filing data are used for estimating plan risk and claims.

Under the ACA, risk adjustment redistributes money from firms drawing below-average risk customers to firms drawing above-average consumers. Transfers between firms must sum to zero, which differs from Medicare Advantage (MA) where risk adjustment payments to MA plans are tied to Traditional Medicare and are usually positive. The objectives of risk adjustment are to prevent unraveling of generous options and to disincentivize firms from attempting to select the lowest-risk consumers (known as "cherry-picking") as a means of reducing costs. All metal plans in the state's individual market, including off-exchange plans, are in the same risk adjustment pool. Catastrophic plans are risk-adjusted separately. Figure 2 summarizes risk adjustment transfers in our sample by metal tier. The most generous tier of platinum plans received substantial risk adjustment transfers whereas the least generous tier of bronze plans paid risk adjustment transfers. This is consistent with more generous plans in the ACA exchanges being adversely selected.

\section{Model and Estimation}

We construct a two-stage model where insurers first set premiums and households then select plans. Our model closely follows the one in Saltzman (2021). We present and estimate our model starting with household plan selection.

\subsection{Demand}

In our demand model, households select the plan maximizing their (indirect) utility

$$
U_{i j t} \equiv \beta_{i}^{p} p_{i j t}\left(\mathbf{p}_{t}\right)+\beta_{i j}^{y} y_{i j(t-1)}+x_{i j}^{\prime} \beta^{x}+w_{i t}^{\prime} \beta^{w}+\xi_{j}+\epsilon_{i j t}^{d}
$$

where $\mathbf{p}_{t}$ is the base premiums for all plans in year $t, p_{i j t}\left(\mathbf{p}_{t}\right)$ is consumer $i$ 's premium as a function of plan $j$ 's base premium, $y_{i j(t-1)}$ is a lagged choice indicator, $x_{i j}$ is observable non-premium plan characteristics such as the plan AV and network type, $w_{i t}$ is the vector of household demographics

\footnotetext{
${ }^{11}$ Reinsurance was in effect for 2014-2016 and helped insurers cover consumers with the highest utilization. The nationwide budget was $\$ 10$ billion in 2014, \$6 billion in 2015, and \$4 billion in 2016.
} 
Figure 2: Average Risk Adjustment Received (Paid) By Plans in Each Metal Level

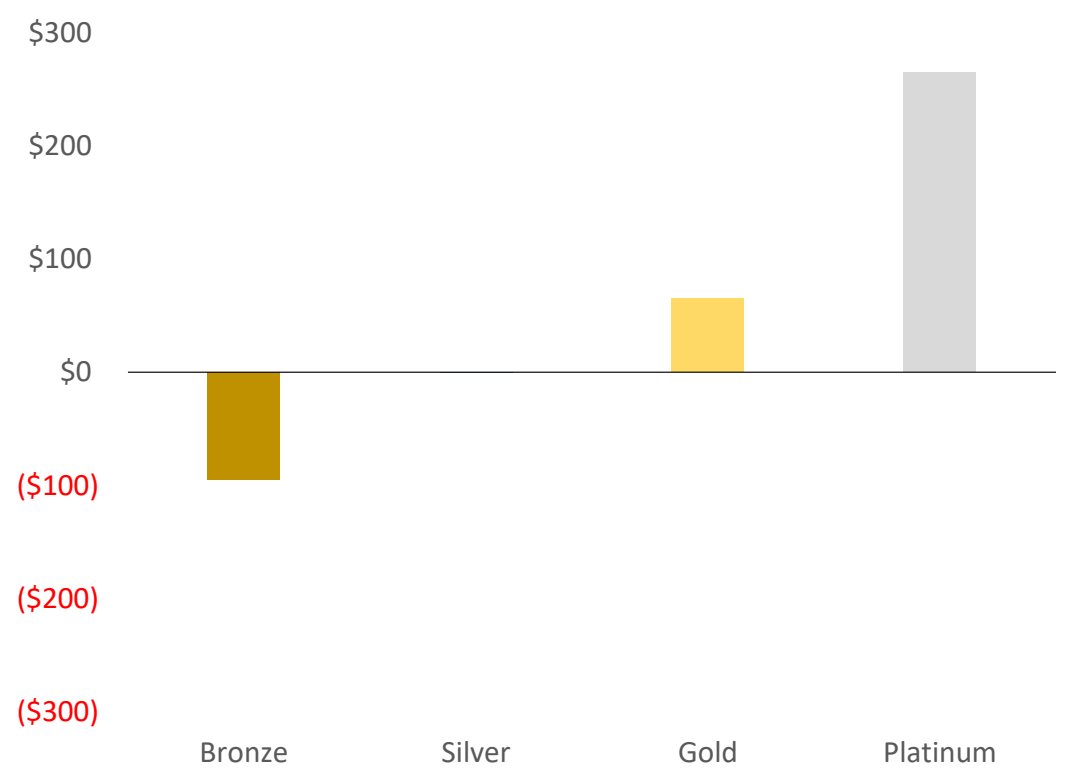

Notes: Figure shows the per-member per-month risk adjustment transfer for plans in each metal tier. A positive transfer indicates that a plan received a transfer because its enrollees had above-average risk, whereas a negative transfer indicates a plan paid a transfer because its enrollees had below-average risk. 
summarized in Table $1, \xi_{j}$ is unobserved plan characteristics, and $\epsilon_{i j t}^{d}$ is an error term. The premium parameter $\beta_{i}^{p}=\beta^{p}+w_{i t}^{\prime} \phi$ is a function of household demographics and the inertia parameter $\beta_{i j}^{y}=\beta^{y}+x_{i j}^{\prime} \kappa+w_{i t}^{\prime} \nu$ is a function of both plan characteristics and household demographics. Premium subsidies decrease the premium $p_{i j t}\left(\mathbf{p}_{t}\right)$ paid by the household and CSRs increase the plan AV in equation (1). Define $U_{i 0 t}=\beta_{i}^{p} \rho_{i t}+\epsilon_{i 0 t}$ as the utility of the outside option (i.e., forgoing insurance), where $\rho_{i t}$ is the household's penalty for not having insurance.

\subsubsection{Premium Subsidies and Regulation}

The household premium including subsidies is

$$
p_{i j t}\left(\mathbf{p}_{t}\right)=\max \{\underbrace{\sigma_{i t} p_{j m t}}_{\begin{array}{c}
\text { full } \\
\text { premium }
\end{array}}-\underbrace{\max \left\{\sigma_{i t} p_{b m t}-\zeta_{i t}, 0\right\}}_{\text {premium subsidy }}, 0\}
$$

where $p_{j m t}$ is the plan base premium, $p_{b m t}$ is the benchmark plan base premium, and $\zeta_{i t}$ is the income contribution limit. The unsubsidized premium equals the product of the plan base premium and the household-specific rating factor $\sigma_{i t}$. The rating factor characterizes the limited ways in which insurers' premiums can vary with household characteristics. ACA premiums can only vary by age, tobacco usage, and geography. The ratio of premiums for a 64-year-old vs. a 21 -year-old cannot be greater than 3-to-1. California is one of several states that prohibits tobacco rating. The California exchange is divided into 19 rating areas within which premiums cannot vary, conditional on age.

The ACA's premium subsidy is designed to limit the household's outlay for the benchmark plan to a certain percentage of its income. It is computed as the difference between the benchmark plan premium $\left(\sigma_{i t} p_{b m t}\right)$ and the income-based contribution limit $\zeta_{i t}$. The benchmark plan is the plan with the second-lowest premium in the household's choice set and can vary between households because of partial firm entry and heterogeneous pricing across state rating areas. The income-based contribution limit was $2 \%$ of income for consumers with income of $100 \%$ of the federal poverty level (FPL) and 9.5\% of income for consumers with income of 400\% of FPL in 2014 (these percentages change slightly each year). For example, a single consumer earning $100 \%$ of FPL (\$11,670 in 2014) would have a contribution limit of $\$ 233$ per year or $\$ 19$ per month; the consumer's monthly premium subsidy would be $\$ 181$ if the full benchmark plan premium were $\$ 200$. This $\$ 181$ subsidy could be used for any metal plan (catastrophic plans do not qualify for subsidies). If some bronze plans have a full premium below $\$ 181$, the subsidy would be reduced to ensure the household's premium is nonnegative. Many consumers may therefore have access to "free" plans, a fact which 
we exploit to identify the premium parameter $\beta_{i}^{p}$ as discussed in the next subsection.

\subsubsection{Demand Estimation and Identification}

To estimate the demand parameters, we assume the error term $\epsilon_{i j t}^{d}$ has the generalized extreme value distribution such that equation (1) defines a nested logit choice model at the consumer level. We create two nests, including one with all available exchange plans and a second with the outside option. Following Train (2009), the household choice probabilities are then:

$$
q_{i j t}\left(\mathbf{p}_{t} ; \boldsymbol{\beta}\right)=\frac{e^{V_{i j t}\left(\mathbf{p}_{t}\right) / \lambda}\left(\sum_{j} e^{V_{i j t}\left(\mathbf{p}_{t}\right) / \lambda}\right)^{\lambda-1}}{1+\left(\sum_{j} e^{V_{i j t}\left(\mathbf{p}_{t}\right) / \lambda}\right)^{\lambda}}
$$

where $V_{i j t}\left(\mathbf{p}_{t}\right) \equiv \beta_{i}^{p} p_{i j t}\left(\mathbf{p}_{t}\right)+\beta_{i j}^{y} y_{i j(t-1)}+x_{i j}^{\prime} \beta^{x}+w_{i t}^{\prime} \beta^{w}+\xi_{j}$. The vector of utility weights is $\boldsymbol{\beta}=\left(\beta_{i}^{p}, \beta_{i j}^{y}, \beta^{x}, \beta^{w}\right)$ and $\lambda$ is the nesting parameter. As discussed in Section 2.2 below, we estimate the model using a two-step feasible generalized method of moments (GMM) estimator.

Subsidized premiums vary at the household, market, and insurer level. A natural concern is that premiums are endogenous and correlated with unobserved plan quality, which might reflect customer service or provider networks. We include insurer-market fixed effects to control for timeinvariant plan quality. Conditional on those fixed effects, there are multiple additional sources of plausibly exogenous variation for identification of the premium parameter $\beta_{i}^{p}$. First, the phasing in of the mandate penalty between 2014 and 2016 and elimination of the penalty in 2019 creates exogenous variation in premiums relative to the outside option. Second, nonlinearities in equation (2) create exogenous premium variation between plans within a given household's choice set. For example, some bronze plans are available free to some households because the subsidy exceeds the full premium due to exogenous household characteristics; the set of free plans varies across household characteristics, market, and time.

Another identification challenge we face is that persistence in plan choices may reflect persistent unobserved preference heterogeneity, rather than inertia. We identify the inertia parameter $\beta_{i j}^{y}$ by leveraging two key features of our empirical setting. First, because we observe the first year of exchange's enrollment, every consumer in our data made at least one active choice upon entry, either in 2014 or in a subsequent year when the consumer first became eligible for exchange coverage. This allows us to compare, for example, 2015 enrollment decisions for consumers enrolled in a Health Net silver plan in 2014 with those of consumers ineligible for the exchange in 2014. The differential market shares of the Health Net silver plan in 2015 across these two groups provides evidence regarding the existence and extent of inertia. Although newly-eligible enrollees in 2015 
may have different preferences than 2014 enrollees, we can leverage this type of identification across multiple years and across enrollees initially enrolled in many different plan types. Second, some consumers made additional active decisions if their previous plans were no longer offered or if they were prohibited from purchasing their previous plans (e.g., young adults cannot buy a catastrophic plan upon turning 30). The most prominent example of this phenomenon occurred when Anthem exited most markets in 2018. Intuitively, we can compare the 2018 plan choices of 2017 Anthem enrollees, in markets where Anthem remained vs. those where Anthem exited.

\subsubsection{Demand Results}

We estimate the utility weights in equation (1) using a 5\% sample of the data. ${ }^{12}$ Table 4 summarizes the out-of-sample fit of our model, for four different specifications. Specification 1 is the most parsimonious and models choices as a function of all plan and enrollee characteristics, including insurer fixed effects. Specification 2 adds interactions between premium and household characteristics (i.e., allowing low-income families to be more price-sensitive) and between lagged plan choice and both plan and household characteristics (i.e., allowing inertia to be higher among older consumers, or among Blue Shield enrollees). Specification 3 controls for insurer-market fixed effects. Specifications (1)-(3) are estimated on the pooled 5\% sample; specification 4 estimates the model separately for 4 age-income combinations. ${ }^{13}$ For each specification, we compare the model predictions to the observed data in a hold-out sample not used in estimation. Specification 2 results in a better out-of-sample fit than specification 1, particularly for matching the share of enrollment by metal tier. Including insurer-market fixed effects (specification 3) does not yield any appreciable gains in fit. Specification 4 matches enrollment by metal tier slightly better than specification 2, but performs worse in matching plan switching rates and adds considerable computational complexity for our subsequent analyses. We consider specification 2 to be our most preferred and use this specification for all subsequent analyses in this paper. Detailed parameter estimates are available in Appendix Table A1.

The first four columns of Table 5 display price elasticities of demand by household characteristics. We show both own-premium elasticities and elasticities of exchange coverage overall. The sensitivity of a subsidized consumer's demand to a premium change is

\footnotetext{
${ }^{12}$ We also estimated the model on larger samples and obtained nearly identical estimates. We encountered significant computational challenges using samples larger than $5 \%$ of the data. Therefore, we perform the estimation with a $5 \%$ sample.

${ }^{13}$ These combinations are (1) below age 45 and income below $200 \%$ of FPL; (2) below age 45 and income above $200 \%$ of FPL; (3) above age 45 and income below 200\% of FPL; and (4) above age 45 and income above $200 \%$ of FPL.
} 
Table 4: Assessing Out-Of-Sample Model Fit

\begin{tabular}{lccccc}
\hline & & \multicolumn{4}{c}{ Estimated Model } \\
\cline { 3 - 6 } & Data & $(1)$ & $(2)$ & $(3)$ & $(4)$ \\
\hline Specification & & & & $\checkmark$ & $\checkmark$ \\
Interactions & N/A & & $\checkmark$ & $\checkmark$ & $\checkmark$ \\
Insurer-Market FEs & N/A & & & & \\
Age-Income & N/A & & & & \\
\hline Enrollment & & & & & \\
Total Enrollment & $1,751,574$ & $1,747,292$ & $1,747,161$ & $1,747,140$ & $1,747,311$ \\
Bronze & $27.5 \%$ & $25.5 \%$ & $26.6 \%$ & $26.5 \%$ & $27.6 \%$ \\
Silver & $61.9 \%$ & $62.3 \%$ & $62.6 \%$ & $62.6 \%$ & $61.9 \%$ \\
Gold & $6.4 \%$ & $7.2 \%$ & $6.5 \%$ & $6.6 \%$ & $6.5 \%$ \\
Platinum & $4.1 \%$ & $4.9 \%$ & $4.3 \%$ & $4.4 \%$ & $4.0 \%$ \\
Anthem & $20.8 \%$ & $20.6 \%$ & $20.7 \%$ & $20.7 \%$ & $20.7 \%$ \\
Blue Shield & $27.7 \%$ & $27.5 \%$ & $27.4 \%$ & $27.3 \%$ & $27.4 \%$ \\
Health Net & $14.3 \%$ & $14.5 \%$ & $14.5 \%$ & $14.5 \%$ & $14.4 \%$ \\
Kaiser & $26.0 \%$ & $25.9 \%$ & $25.9 \%$ & $25.9 \%$ & $26.1 \%$ \\
Other Insurer & $11.3 \%$ & $11.5 \%$ & $11.6 \%$ & $11.5 \%$ & $11.4 \%$ \\
Switching Rate & $17.4 \%$ & $15.2 \%$ & $15.3 \%$ & $15.2 \%$ & $14.4 \%$ \\
\hline
\end{tabular}

Notes: Table compares our data to the out-of-sample fit of 4 alternative specifications of utility equation (1). All specifications were estimated using a 5\% sample of the data. The first panel defines the specification for each of the 4 models. Specifications (2)-(4) include interaction terms between 1) the premium and household characteristics; and 2) the lagged choice variable and household characteristics; and 3) the lagged choice variable and product characteristics. Specification (3) also includes insurer-market fixed effects. Specification (4) estimates the model separately for 4 age-income bins (age above and below 45, income above and below $200 \%$ of FPL). The second panel reports average annual enrollment, market shares by metal level and insurer, and the percentage of renewing consumers who switched plans. 


$$
\frac{\partial q_{i k t}\left(\mathbf{p}_{t}\right)}{\partial p_{j m t}}=\sum_{l \in J_{m t}} \frac{\partial q_{i k t}\left(\mathbf{p}_{t}\right)}{\partial p_{i l t}\left(\mathbf{p}_{t}\right)} \frac{\partial p_{i l t}\left(\mathbf{p}_{t}\right)}{\partial p_{j m t}}
$$

for all plans $j, k$, with $^{14}$

$$
\frac{\partial p_{i l t}\left(\mathbf{p}_{t}\right)}{\partial p_{j m t}}=\left\{\begin{array}{ll}
0 & l=j, j=b \\
\sigma_{i t} & l=j, j \neq b \\
-\sigma_{i t} & l \neq j, j=b \\
0 & l \neq j, j \neq b
\end{array} .\right.
$$

Intuitively, a small premium increase for a non-benchmark plan leads to consumers paying more for only that plan. However, a small premium increase for the benchmark plan increases the consumer's subsidy. This implies that the consumer's contribution to the benchmark plan is unchanged. However, because of the larger subsidy, the consumer would then pay less for all non-benchmark plans.

Our elasticity estimates are similar to previous estimates (Domurat, 2018; Drake, 2019; Saltzman, 2019; Tebaldi, 2020). Consumers with lower incomes and younger consumers are more priceelastic.

The last column of Table 5 presents the annual switching costs implied by our parameter estimates. On average, consumers were willing to pay $\$ 2,324$ more in annual premiums to remain in their previous plan, rather than switching to another plan with identical characteristics. Higherincome consumers and adults over age 55 had switching costs of about $\$ 3,700$, whereas young adults (ages 18-34) had switching costs of about $\$ 1,500$. We also find that consumers were more attached to some plans than others, though these differences were not as stark. For example, "the Blues"-Anthem Blue Cross and Blue Shield of California-were associated with larger switching costs.

Our estimates of inertia are large relative to annual premiums - $\$ 2,324$ is $44 \%$ of the average enrollee's \$5,307 in annual premium expenditures. Handel (2013) estimates a switching cost of $\$ 2,032$ per enrollee-year for employer-sponsored health insurance coverage and Polyakova (2016) estimates switching costs of $\$ 400-\$ 600$ per enrollee-year for Medicare Part D, which covers only prescription drugs.

\footnotetext{
${ }^{14}$ The formula assumes that the subsidy does not exceed the full, unsubsidized premium.
} 
Table 5: Elasticities and Annual Switching Costs

\begin{tabular}{|c|c|c|c|c|c|}
\hline & \multicolumn{2}{|c|}{ Own-Premium } & \multicolumn{2}{|c|}{ Exchange Coverage } & \multirow[b]{2}{*}{$\begin{array}{c}\text { Annual } \\
\text { Plan } \\
\text { Switching } \\
\text { Cost }\end{array}$} \\
\hline & Elasticity & $\begin{array}{l}\text { Semi- } \\
\text { Elasticity }\end{array}$ & Elasticity & $\begin{array}{l}\text { Semi- } \\
\text { Elasticity }\end{array}$ & \\
\hline Overall & -7.76 & -14.87 & -0.24 & -0.56 & $\$ 2324$ \\
\hline \multicolumn{6}{|l|}{ Income (\% of FPL) } \\
\hline $0-250$ & -8.23 & -15.84 & -0.26 & -0.60 & $\$ 2064$ \\
\hline $250-400$ & -6.92 & -13.53 & -0.22 & -0.51 & $\$ 2648$ \\
\hline $400+$ & -5.47 & -10.99 & -0.17 & -0.42 & $\$ 3750$ \\
\hline \multicolumn{6}{|l|}{ Gender } \\
\hline Female & -7.43 & -14.27 & -0.23 & -0.53 & $\$ 2400$ \\
\hline Male & -8.14 & -15.51 & -0.25 & -0.58 & $\$ 2274$ \\
\hline \multicolumn{6}{|l|}{ Age } \\
\hline $0-17$ & -10.59 & -18.48 & -0.33 & -0.69 & $\$ 1663$ \\
\hline $18-34$ & -11.56 & -20.17 & -0.36 & -0.75 & $\$ 1513$ \\
\hline $35-54$ & -8.25 & -14.38 & -0.26 & -0.53 & $\$ 2148$ \\
\hline $55+$ & -5.33 & -9.26 & -0.16 & -0.34 & $\$ 3710$ \\
\hline \multicolumn{6}{|l|}{ Race/Ethnicity } \\
\hline Asian & -8.69 & -16.45 & -0.27 & -0.62 & $\$ 1778$ \\
\hline Black & -7.55 & -14.45 & -0.24 & -0.54 & $\$ 2217$ \\
\hline Hispanic & -9.27 & -17.46 & -0.29 & -0.65 & $\$ 1769$ \\
\hline Other & -7.04 & -13.56 & -0.22 & -0.51 & $\$ 2458$ \\
\hline Non-Hispanic White & -6.83 & -13.20 & -0.21 & -0.49 & $\$ 2653$ \\
\hline \multicolumn{6}{|l|}{ Household Size } \\
\hline Single & -7.75 & -14.85 & -0.24 & -0.56 & $\$ 2410$ \\
\hline Family & -7.77 & -14.89 & -0.24 & -0.56 & $\$ 2164$ \\
\hline \multicolumn{6}{|l|}{ Insurer } \\
\hline Anthem & & & & & $\$ 2564$ \\
\hline Blue Shield & & & & & $\$ 3080$ \\
\hline Kaiser & & & & & $\$ 2204$ \\
\hline Health Net & & & & & $\$ 2061$ \\
\hline Other Insurer & & & & & $\$ 1910$ \\
\hline \multicolumn{6}{|l|}{ HMO } \\
\hline Non-HMO & & & & & $\$ 2021$ \\
\hline $\mathrm{HMO}$ & & & & & $\$ 2805$ \\
\hline
\end{tabular}

Notes: Table reports elasticities and switching costs by demographic group. The first and second columns consider how a plan's demand responds to a change in its own (unsubsidized) premium. The third and fourth columns consider how total exchange enrollment responds to a change in all exchange premiums. The semi-elasticities defined in the second and fourth columns are calculated for a $\$ 100$ change in annual premiums. The fifth column reports the annual cost of a household switching to a new plan, which equals $-12 \frac{\beta_{i j}^{y}}{\beta_{i}^{p}}$. All plan means are computed using market shares as weights. 


\subsection{Supply}

In the first stage where firms set premiums, we account for the complex regulatory and subsidy structure in the ACA exchanges. Firms set the base premium $p_{j m t}$ for each plan $j$ that they sell to maximize expected profit

$$
\pi_{f t}\left(\mathbf{p}_{t}\right)=R_{f t}\left(\mathbf{p}_{t}\right)-C_{f t}\left(\mathbf{p}_{t}\right)+R A_{f t}\left(\mathbf{p}_{t}\right)+R I_{f t}\left(\mathbf{p}_{t}\right)-V_{f t}\left(\mathbf{p}_{t}\right)-F C_{f t} .
$$

Expected profit includes total premium revenue $R_{f t}\left(\mathbf{p}_{t}\right)$, total claims $C_{f t}\left(\mathbf{p}_{t}\right)$, risk adjustment received $R A_{f t}\left(\mathbf{p}_{t}\right)$, reinsurance received $R I_{f t}\left(\mathbf{p}_{t}\right)$, variable administrative costs $V_{f t}\left(\mathbf{p}_{t}\right)$ such as commissions, and the fixed cost $F C_{f t}$ of participating in the marketplace.

Our model endogenizes risk adjustment transfers. Using our notation, we can write the average plan risk adjustment formula used in the ACA exchanges (as specified in Pope et al. (2014)'s first appendix) as

$$
r a_{j m t}\left(\mathbf{p}_{t}\right)=\left(\frac{r_{j m t}\left(\mathbf{p}_{t}\right) \sum_{m \in M, l \in J_{m t}} q_{l m t}(p)}{\sum_{m \in M, l \in J_{m t}} r_{j m t}\left(\mathbf{p}_{t}\right) q_{l m t}\left(\mathbf{p}_{t}\right)}-\frac{h_{j} \sum_{m \in M, l \in J_{m t}} q_{l m t}(p)}{\sum_{m \in M, l \in J_{m t}} h_{l} q_{l m t}\left(\mathbf{p}_{t}\right)}\right) \bar{p}
$$

where $r_{j m t}\left(\mathbf{p}_{t}\right)$ is the risk score determined by CMS as a function of the plan AV and enrollee characteristics, $h_{j}$ is an expected utilization factor set by regulation that captures the plan AV and moral hazard, and $\bar{p}$ is the weighted market average premium. The total transfer $R A_{j m t}\left(\mathbf{p}_{t}\right)$ equals

$$
R A_{j m t}\left(\mathbf{p}_{t} ; \boldsymbol{\theta}\right)=r a_{j m t}\left(\mathbf{p}_{t}\right) q_{j m t}\left(\mathbf{p}_{t}\right)=\left[r s_{j m t}\left(\mathbf{p}_{t}\right)-u s_{j m t}\left(\mathbf{p}_{t}\right)\right] R_{t}\left(\mathbf{p}_{t} ; \boldsymbol{\beta}\right)
$$

The firm's total transfer $R A_{f t}\left(\mathbf{p}_{t}\right)=\sum_{m \in M, j \in J_{f m t}} R A_{j m t}\left(\mathbf{p}_{t}\right)$. Total premium revenue in the market is $R_{t}\left(\mathbf{p}_{t}\right)=\sum_{f} R_{f t}\left(\mathbf{p}_{t} ; \boldsymbol{\beta}\right)$. The plan's "risk share" $r s_{j m t}\left(\mathbf{p}_{t}\right)$ accounts for adverse selection, moral hazard, and plan AV, whereas the plan's utilization share accounts for moral hazard and plan AV. Thus, the plan's relative risk due to adverse selection is captured by the difference between the plan's risk share and utilization share. The plan's risk share of total claims $r s_{j m t}\left(\mathbf{p}_{t}\right)$ in formula (6) then equals:

$$
r s_{j m t}\left(\mathbf{p}_{t}\right)=\frac{r_{j m t}\left(\mathbf{p}_{t}\right) q_{j m t}\left(\mathbf{p}_{t}\right)}{\sum_{m \in M, l \in J_{m t}} r_{l m t}\left(\mathbf{p}_{t}\right) q_{l m t}\left(\mathbf{p}_{t}\right)}
$$

where $J_{m t}$ is all plans offered in market $m$ and year $t$. Although plan risk scores are not directly observed in our data, we observe all other variables in formula (6) and can hence back out the plan risk scores from equation (6). The plan's "utilization share" $u s_{j m t}\left(\mathbf{p}_{t}\right)$ equals:

$$
u s_{j m t}\left(\mathbf{p}_{t}\right)=\frac{h_{j} q_{j m t}\left(\mathbf{p}_{t}\right)}{\sum_{m \in M, l \in J_{m t}} h_{l} q_{l m t}\left(\mathbf{p}_{t}\right)} .
$$

If the risk share exceeds the utilization share, then the plan has high risk compared to expected uti- 
lization and it receives a transfer from the risk adjustment program. If the utilization share exceeds the risk share, then the plan has low risk compared to expected utilization and it pays a transfer.

The first-order conditions corresponding to equation (5) are:

$$
M R_{j m t}\left(\mathbf{p}_{t}\right)+M R A_{j m t}\left(\mathbf{p}_{t}\right)=\left(1-\iota_{f t}\right) M C_{j m t}\left(\mathbf{p}_{t}\right)+M V_{j t}\left(\mathbf{p}_{t}\right)
$$

where $\iota_{f t}$ is the AV of the reinsurance contract. Note that this solution accounts for portfolio effects in which each firm internalizes the effects of one plan's premium on the enrollment in other plans it offers. Detailed formulas for marginal revenue $M R_{j m t}\left(\mathbf{p}_{t}\right) \equiv \frac{\partial R_{f t}\left(\mathbf{p}_{t}\right)}{\partial q_{j m t}\left(\mathbf{p}_{t}\right)}$, marginal claims $M C_{j m t}\left(\mathbf{p}_{t}\right) \equiv \frac{\partial C_{f t}\left(\mathbf{p}_{t}\right)}{\partial q_{j m t}\left(\mathbf{p}_{t}\right)}$, marginal transfers $M R A_{j m t}\left(\mathbf{p}_{t}\right)=\frac{\partial R A_{f t}\left(\mathbf{p}_{t}\right)}{\partial q_{j m t}\left(\mathbf{p}_{t}\right)}$, and marginal variable administrative costs $M V_{j t}\left(\mathbf{p}_{t}\right)$ are given in Appendix B. To reduce the computational burden of estimating and using the model for counterfactual simulations, we assume firm entry decisions are exogenous. In alternative market and policy settings, firms may decide to enter or exit specific markets or the exchange altogether, and any such shifts in market participation may have implications for our welfare estimates in the next section. Our analysis should thus be considered partial equilibrium.

We use our enrollment and insurer rate filing data to estimate every term in equation (7). Our strategy is to write equation (7) in terms of the household choice probabilities $q_{i j t}\left(\mathbf{p}_{t}\right)$, plan risk scores $r_{j m t}\left(\mathbf{p}_{t}\right)$, and plan average claims $c_{j m t}\left(\mathbf{p}_{t}\right)$. We calculate the household choice probabilities using equation (3). We do not observe all of the enrollee characteristics used by regulators to compute plan risk scores, and our simulations require a model of how counterfactual enrollment patterns will impact plans' risk scores and claims. Accordingly, we predict risk scores as a function of plan AV and observed household characteristics using the following estimating equation:

$$
\ln r_{j m t}\left(\mathbf{p}_{t} ; \boldsymbol{\beta}, \boldsymbol{\gamma}\right)=\sum_{d \in D} \gamma^{d} s_{d j m t}\left(\mathbf{p}_{t} ; \boldsymbol{\beta}\right)+M T_{j}^{\prime} \gamma^{M T}+\epsilon_{j m t}^{r}
$$

where $s_{d j m t}(\cdot)$ is the share of plan $j$ 's enrollment with demographic characteristic $d, M T_{j}$ is a vector of metal fixed effects, and $\epsilon_{j m t}^{r}$ is the error term. The parameter vector $\gamma=\left(\gamma^{d}, \gamma^{M T}\right)$ captures how plans' risk scores scale with demographic variables and plan generosity. We predict average claims using the estimating equation:

$$
\ln c_{j m t}\left(\mathbf{p}_{t} ; \boldsymbol{\beta}, \boldsymbol{\gamma}, \boldsymbol{\theta}\right)=\theta^{r} \ln r_{j m t}\left(\mathbf{p}_{t} ; \boldsymbol{\beta}, \boldsymbol{\gamma}\right)+x_{j}^{\prime} \theta^{x}+\theta^{u} u_{t}+n_{m}^{\prime} \theta^{n}+\epsilon_{j m t}^{c}
$$

where $x_{j}$ is an HMO dummy, $u_{t}$ is a linear trend, $n_{m}^{\prime}$ are market fixed effects, $\epsilon_{j m t}^{c}$ is an error term, and $\boldsymbol{\theta}=\left(\theta^{r}, \theta^{x}, \theta^{u}, \theta^{n}\right)$ are parameters to be estimated.

We estimate the model parameters using four groups of moments: (1) moments that match the predicted household choice probabilities from equation (3) with the observed plan choices; (2) 
moments that match observed and predicted risk scores in equation (8); (3) moments that match observed and predicted average claims in equation (9); and (4) the first-order conditions in equation (7). Because there are more moment conditions than parameters, we use two-step feasible GMM to estimate the model parameters.

Table 6 summarizes our estimates of the parameters $\gamma$ and $\boldsymbol{\theta}$. As expected, risk scores are increasing monotonically across the metal tiers. The bottom panel reports the estimated coefficients in the claims equation. If the predicted risk score increases by one percent, average claims are also predicted to increase by about one percent. For plans with the same risk score, HMOs are predicted to have $12 \%$ lower average claims, which is similar to the efficiency advantage of HMOs used in Cutler and Reber (1998). Predicted claims are also increasing about $1.3 \%$ each year.

Table 6: Supply Parameter Estimates

\begin{tabular}{lccc}
\hline \hline \multicolumn{2}{c}{ Risk Score Parameters $(\gamma)$} & \multicolumn{2}{c}{ Average Claims Parameters $(\boldsymbol{\theta})$} \\
Silver & $0.568^{* * *}$ & Log Risk Score & $1.035^{* * *}$ \\
& $(0.030)$ & & $(0.005)$ \\
Gold & $0.783^{* * *}$ & HMO & $-0.122^{* * *}$ \\
& $(0.052)$ & & $(0.008)$ \\
Platinum & $1.109^{* * *}$ & Trend & $0.013^{* * *}$ \\
Share Ages 18 to 34 & $(0.053)$ & & $(0.002)$ \\
Share Ages 35 to 54 & $-0.819^{*}$ & Anthem & $0.272^{* * *}$ \\
& $(0.462)$ & & $(0.018)$ \\
Share Hispanic & -0.783 & Blue Shield & $0.175^{* * *}$ \\
& $(0.681)$ & & $(0.020)$ \\
& $(0.222)$ & Kaiser & $0.203^{* * *}$ \\
& & & $(0.022)$ \\
& & Health Net & $0.092^{* * *}$ \\
\hline
\end{tabular}

Notes: Robust standard errors are in parentheses $\left({ }^{* * *}\right.$ indicates statistical significance at the $1 \%$ level, ${ }^{* *}$ at the $5 \%$ level, and ${ }^{*}$ at the $10 \%$ level).

\section{Counterfactual Simulations}

The key focus of our paper is a series of simulation exercises in which we use the above model estimates to: (1) estimate the effect of removing inertia on equilibrium premiums, enrollment, and welfare in the observed ACA setting; (2) evaluate how the effects of eliminating inertia would change 
in the absence of firm market power and/or risk adjustment; and (3) provide insight into how three significant features in managed competition-the design of premium subsidies, consumer churn between markets, and provider network generosity, each of which is sensitive to policy choicesinteract with inertia.

\subsection{Simulation Methodology}

We assumed that the observed ACA premiums define a Nash equilibrium that satisfies the firms' first-order conditions for profit maximization (i.e., equation (7)) to estimate the model. This equilibrium occurs in the ACA setting where consumers have inertia, firms have market power, and risk adjustment is in effect. In our main simulation analysis, we construct counterfactual scenarios that involve combinations of three changes: eliminating inertia, eliminating risk adjustment, and eliminating firm market power. We simulate the elimination of inertia by setting the lagged choice variables in the consumer's utility function to zero and re-solving for the equilibrium premiums. We simulate the elimination of risk adjustment by removing the marginal transfer from the first-order conditions and re-solving for the equilibrium premiums. We simulate the elimination of market power by solving for the vector of premiums that sets the profit for each plan equal to zero. We run every simulation once for the years 2015-2018 and report a simple average across years.

We also conduct three analyses where we (1) eliminate the ACA's endogenous subsidy; (2) eliminate consumer eligibility churn; and (3) consider the extent to which provider network attachment drives the impact of inertia. We simulate the replacement of the ACA's endogenous subsidy with an exogenous subsidy or voucher by not allowing the observed ACA subsidy to adjust with premiums in alternative scenarios. This change implies that subsidies will remain fixed if all market premiums increase, thus raising consumers' out-of-pocket premiums. It also changes firms' first-order conditions. Mathematically, equation (4) simplifies to

$$
\frac{\partial p_{i l t}\left(\mathbf{p}_{t}\right)}{\partial p_{j m t}}=\left\{\begin{array}{ll}
\sigma_{i t} & l=j \\
0 & l \neq j
\end{array} .\right.
$$

We simulate the elimination of consumer eligibility churn by assuming that, for each year pair $t$ and $t+1$, all consumers eligible in year $t$ maintain eligibility for the exchange in year $t+1$. We then re-solve for the equilibrium premiums. Lastly, we explore whether provider network attachment is a key driver of inertia by re-estimating our entire model with additional interactions between the lagged choice indicator variable and two network variables: network breadth (i.e., the percentage of providers covered in the market (Polsky et al., 2016)) and network inclusivity (i.e., the number 
of providers within each network that overlap with other insurers' networks, as a percentage of the total possible number of shared connections (Graves et al., 2020)). ${ }^{15}$ A limitation of this sensitivity analysis is that provider network data are unavailable for approximately $20 \%$ of plans, requiring us to drop these plans.

For each simulation, we compute total social welfare in year $t$ as $S W_{t} \equiv C S_{t}+\pi_{t}-\delta *$ $G S_{t}$, where $C S_{t}$ is consumer surplus, $\pi_{t}$ is total firm profit, and $G S_{t}$ is total government spending adjusting by a factor $\delta$ to account for the deadweight loss of taxation. We let $\delta=1.3$ following Hausman and Poterba (1987) and Decarolis et al. (2020). Consumer surplus is

$$
C S_{t}=-\sum_{i \in I} \frac{1}{\beta_{i}^{p}} \ln \left(e^{\beta_{i}^{p} * \rho_{i t}}+\left(\sum_{j \in J} e^{V_{i j t}\left(\mathbf{p}_{t}\right) / \lambda}\right)^{\lambda}\right)-\tau \sum_{j \in J}\left[q_{i j t}\left(\mathbf{p}_{t}\right) * \frac{\beta_{i j}^{y} * y_{i j(t-1)}}{-\beta_{i}^{p}}\right]
$$

where the premium parameter $\beta_{i}^{p}$ is in dollars (not hundreds of dollars as in Table 6) and $\tau$ is the fraction of inertia that is assumed to be an error. The first term of equation (11) is the standard nested logit formula for consumer surplus and the second term of equation (11) "corrects" the first term to reflect the fraction $\tau$ of inertia that is an error. The parameter $\tau=0$ if inertia is a true switching cost (e.g., the effort associated with researching plans and re-enrolling) and $\tau=1$ if inertia is the result of behavioral error (e.g., inattention) that impacts choices, but not welfare (Handel and Schwartzstein, 2018). We assume $\tau=1$ in our main analysis, but consider the sensitivity of our results to $\tau<1$. Formula (11) assumes consumer welfare is accurately measured using consumers' revealed preferences. ${ }^{16}$

We compute firm profit using equation (5). Government spending equals the sum of premium subsidies, CSRs, and uncompensated care for the uninsured, minus revenue collected from the mandate penalty. Premium subsidy spending is the sum of subsidies received by each consumer in equation (2). Spending on CSRs is computed as

$$
C S R_{t}=\sum_{i \in I, j \in J} s_{j}^{g} q_{i j t}(p ; \boldsymbol{\beta}) c_{j m t}\left(\mathbf{p}_{t} ; \boldsymbol{\beta}, \boldsymbol{\gamma}, \boldsymbol{\theta}\right)
$$

where $s_{j}^{g}$ is the expected share of claims paid by the government for plan $j .{ }^{17}$ Coughlin et al.

\footnotetext{
${ }^{15}$ There is little variation in network breadth and inclusivity variables over time, implying that the level variables are absorbed into the insurer-market fixed effects. We therefore focus on the interaction terms.

${ }^{16}$ Our model assumes that we can use revealed preference to measure consumer surplus. That is, other than the decision frictions or mistakes associated with inertia, consumers correctly value health coverage and its consequences for their health and mortality. If consumers underestimate the value of health insurance, our welfare calculations could underestimate the reduction in consumer surplus that results from consumers exiting the exchange.

${ }^{17}$ Ignoring moral hazard, the government's expected outlay is $94-70=24 \%$ of claims for the $94 \%$ CSR plan, $87-70=17 \%$ of claims for the $87 \%$ CSR plan, and $73-70=3 \%$ of claims for the $73 \%$ CSR plan. To account for moral hazard, we follow Pope et al. (2014) and assume there is no moral hazard for consumers in the $73 \%$ plan, while
} 
(2014) estimate the per-capita amount of medical costs paid by the government on behalf of the nonelderly uninsured to be $\$ 2,025$. Uncompensated care spending is calculated as the product of $\$ 2,025$ inflated to the timeframe of this study using data from the National Health Expenditure Accounts (Centers for Medicare and Medicaid Services, 2018) and the change in the uninsured population's risk score. Penalty revenue collected by the government equals $\sum_{i \in I} q_{i 0 t} \rho_{i t}$, where $q_{i 0 t}$ is the household's probability of choosing the outside option.

\subsection{Simulation Results: Removing Inertia in the ACA Environment}

We summarize our key simulation results on premiums, coverage, claims, and welfare in Figures 35; more detailed results are available in Appendix Table A2. Figure 3 summarizes the effects of removing inertia on average premiums (panel a), enrollment (panel b), and claims (panel c). Figure 4 summarizes the same results by metal tier. The left-most bars and lines in each figure summarize the Base (ACA) setting where firms have market power and risk adjustment is in place. Panel (a) of Figure 3 indicates that eliminating inertia in the Base setting results in a large decrease $(13.2 \%)$ in equilibrium premiums. This result suggests that inertia is a significant source of firm market power. The premium decrease is due to firms re-pricing; average premiums would decrease only slightly if consumers re-sorted, holding premiums fixed (see Appendix Table A2). Panel (a) of Figure 4 shows that these premium changes occur fairly evenly across the metal tiers.

Panel (b) of Figure 3 indicates that eliminating inertia leads to a $3.1 \%$ decline in total exchange enrollment in the Base setting. This result suggests that for a small share of exchange enrollees, forgoing exchange coverage is optimal in the absence of inertia. Panel (c) of Figure 3 shows that average claims decline by $3.9 \%$ in the Base setting if inertia is removed. This relatively small effect is driven both by reductions in claims within each metal tier that occur when consumers select less costly plans within tier (see panel (c) of Figure 4) and by consumers shifting from more generous metal tiers (e.g., platinum) and to less generous metal tiers (e.g., bronze) (see panel (b) of Figure 4). ${ }^{18}$

The top panel of Figure 5 shows that removing inertia increases average annual per-capita social welfare by $\$ 902$ in the Base setting after the deadweight loss of taxation factor $\delta$ is applied to government spending. ${ }^{19}$ Consumers benefit by reoptimizing plan selection and from reduced

consumers in the $87 \%$ and $94 \%$ plans increase consumption by $12 \%$. Including moral hazard, the $s_{j}^{g}=26.88 \%$ for the 94\% CSR plan, $s_{j}^{g}=19.04 \%$ for the $87 \%$ CSR plan, and $s_{j}^{g}=3 \%$ for the $73 \%$ CSR plan.

${ }^{18}$ The large differences in premiums and claims across metal levels makes the scale of the vertical axes in Figure 4 fairly large, and the effects of inertia visually small by comparison. See Appendix Table A2 for these effects in dollar terms.

${ }^{19}$ All dollar values are reported in Appendix Tables A3 and A4. 
Figure 3: Impact of Inertia on Average Premiums, Coverage, and Claims by Setting

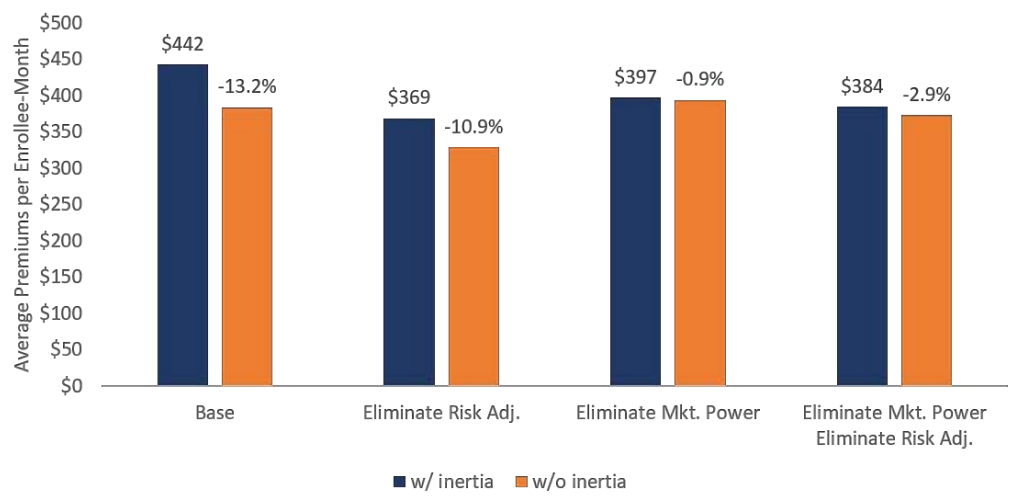

(a) Average Premiums

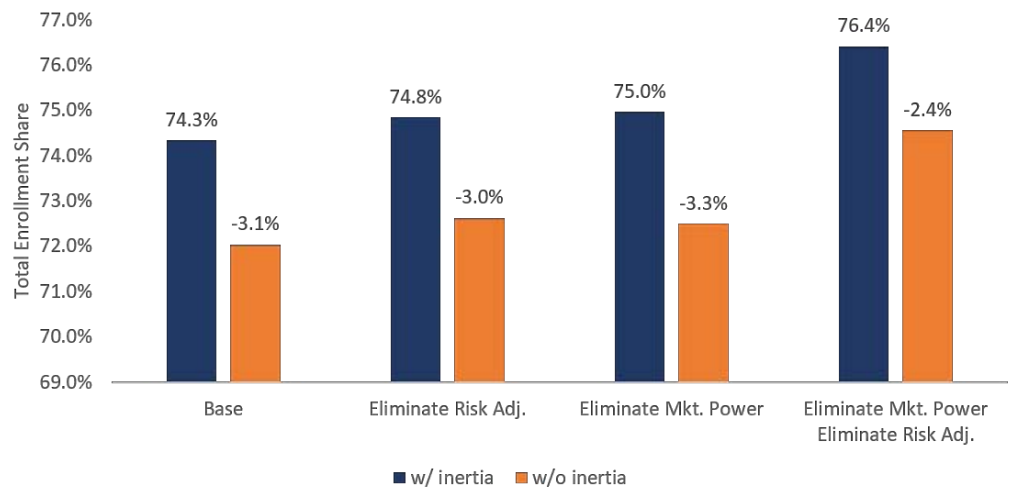

(b) Enrollment Share

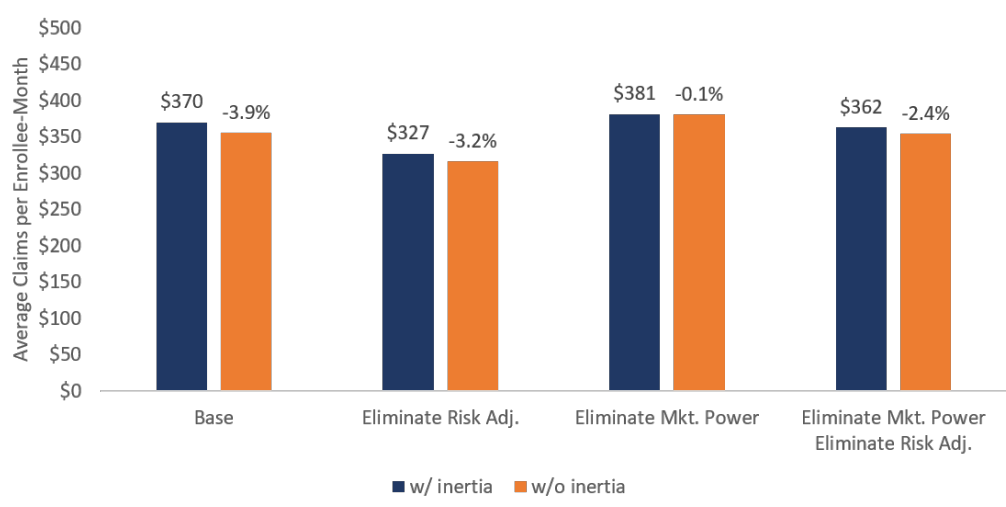

(c) Average Claims

Notes: Figure reports the impact of inertia on average premiums (panel a), share of eligible consumers enrolled in an exchange plan (panel b), and average claims (panel c) by simulated setting. The base setting corresponds to the ACA where firms have market power and risk adjustment is in place. Three modifications to the base setting are considered, including: (1) eliminate risk adjustment; (2) eliminate market power; and (3) eliminate both risk adjustment and market power. 
Figure 4: Impact of Inertia on Premiums, Coverage, and Claims by Metal and Setting

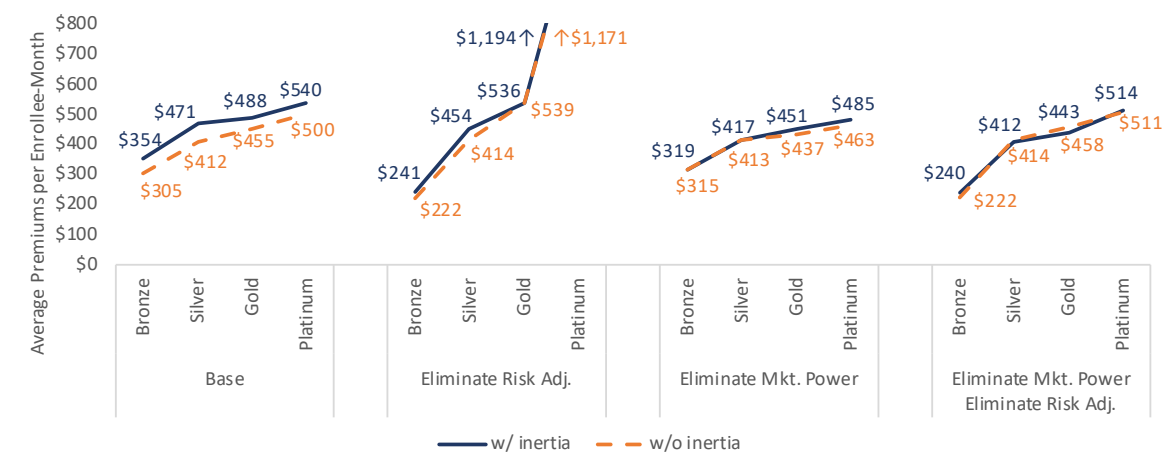

(a) Average Premiums

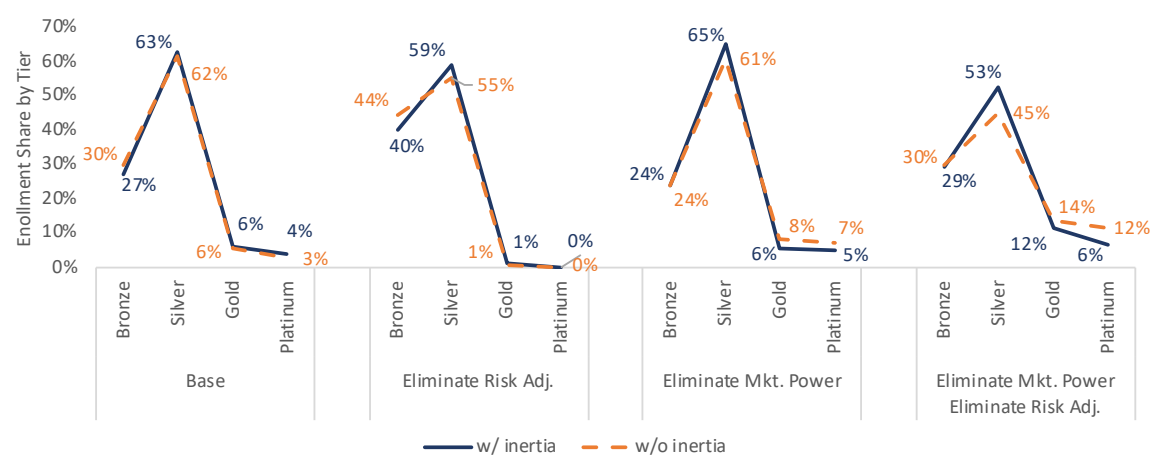

(b) Enrollment Share

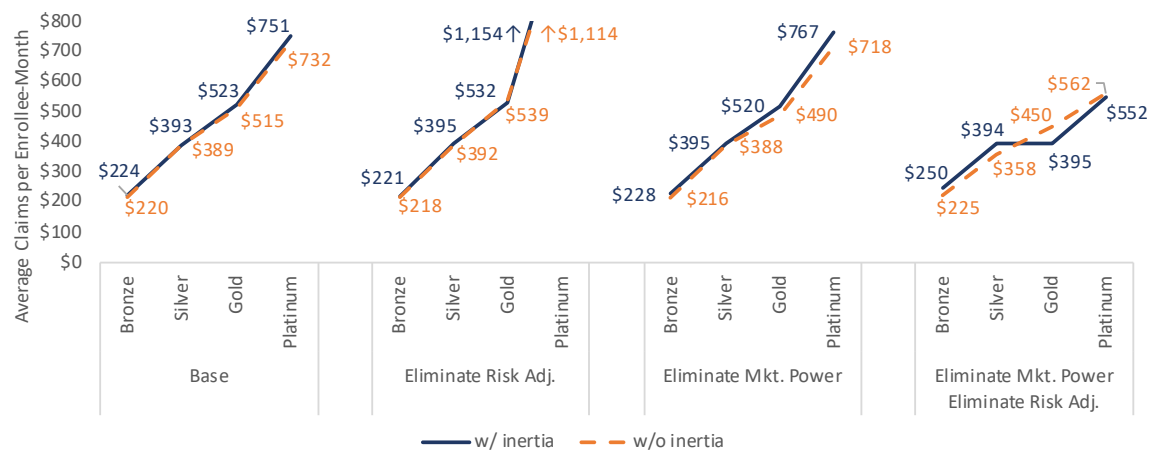

(c) Average Claims

Notes: Figure reports the impact of inertia on average premiums (panel a), share of exchange enrollment (panel b), and average claims (panel c) by metal tier and simulated setting. The base setting corresponds to the ACA where firms have market power and risk adjustment is in place. Three modifications to the base setting are considered, including: (1) eliminating risk adjustment; (2) eliminating market power; and (3) eliminating both risk adjustment and market power. Average platinum premiums and claims are capped at $\$ 800$ in the eliminate risk adjustment setting for presentational purposes. 
premiums. Taxpayers benefit primarily through reductions in premium subsidy spending. Welfare gains for consumers and taxpayers more than offset the $\$ 221$ decrease in per-capita firm profit.

The bottom panel of Figure 5 shows how consumer surplus and net social welfare vary with the proportion of inertia $\tau$ that is assumed to be the result of a behavioral error (the top panel assumes $\tau=1$ ). The positive social welfare impact of eliminating inertia in the Base scenario is fairly robust; over $81 \%$ of inertia would have to represent a true switching cost for the social welfare change to be negative.

\subsection{Simulation Results: Removing Inertia, Market Power, and Risk Adjust- ment}

Next, we evaluate the effects of removing inertia in the absence of risk adjustment and/or market power. Panel (a) in Figure 3 shows that premium decreases are substantially smaller in the alternative settings than the $13.2 \%$ decrease in the Base setting. Removing inertia reduces average premiums by $10.9 \%$ in a counterfactual setting without risk adjustment, $0.9 \%$ in a counterfactual setting without firm market power, and $2.9 \%$ in a counterfactual setting without risk adjustment or firm market power. Panel (b) of Figure 3 indicates total enrollment declines are similar in the three counterfactual settings.

Risk adjustment leads to premium compression across metal tiers, whereas oligopoly competition leads to heterogeneous markups within metal tiers. When risk adjustment and market power are removed, there are accordingly disparate patterns of consumer sorting across versus within metal tiers. Removing inertia amplifies these patterns of consumer sorting and in turn leads to very different premium impacts of inertia across settings. First, consider the effect of removing risk adjustment alone (i.e., with inertia and with market power). Removing risk adjustment eliminates the transfer payments from plans with lower-than-average risk (e.g., bronze) to plans with higher-thanaverage risk (e.g., platinum). As expected, this exacerbates adverse selection across plans, inducing a steeper gradient in premiums across metal tiers (Figure 4, panel a), and a similarly steep gradient

in claims across metal tiers (Figure 4, panel c). In equilibrium, this leads to bronze plans increasing market share from $27 \%$ to $40 \%$, while the market share of the gold and platinum tiers combined nearly unravels from $10 \%$ to $1 \%$ (Figure 4 , panel b). Eliminating inertia in the absence of risk adjustment then has a somewhat smaller effect on average premiums than in the Base setting. This is because removing risk adjustment on its own leads to dramatic shifts in enrollment away from the gold and platinum tiers, and to drops in bronze and silver premiums. The incremental effect of removing inertia is then layered on top of those effects, generating slightly smaller additional pre- 
Figure 5: Impact of Inertia on Average Annual Per-Capita Welfare by Setting

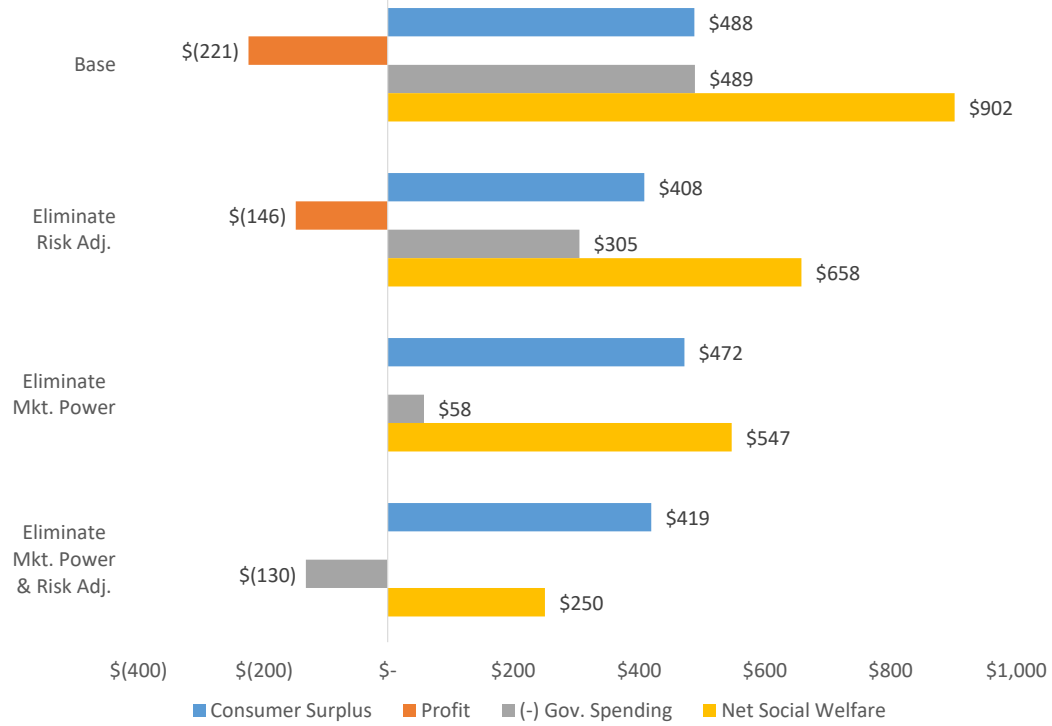

(a) Change in Consumer Surplus, Profit, Government Spending, and Social Welfare

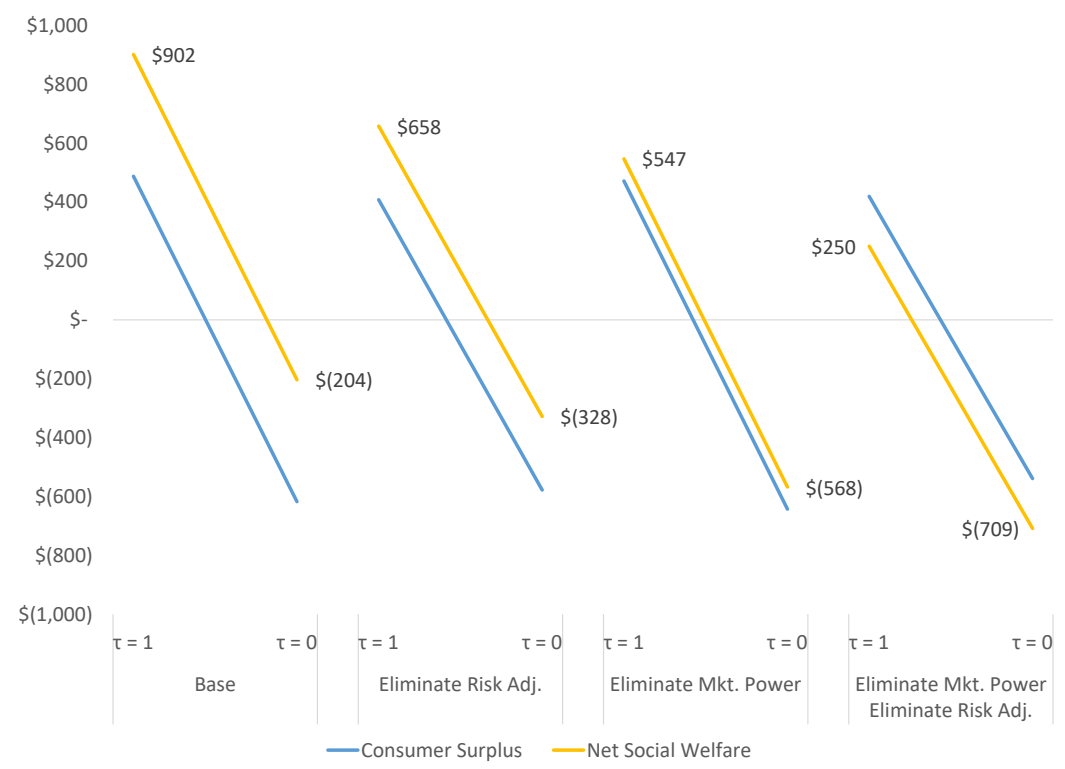

(b) Sensitivity of Welfare to Whether Inertia Is True Switching Cost

Notes: Figure reports the impact of inertia on average annual per-capita welfare by simulated setting. Panel (a) displays consumer surplus, firm profit, government spending (including premium subsidies, CSRs, mandate penalties collected, and uncompensated care), and net social welfare for each simulated scenario. Net social welfare calculation applies the deadweight loss of taxation to government spending before aggregating. Panel (b) shows how consumer surplus and net social welfare vary with the proportion of inertia $\tau$ that is the result of a behavioral error (the first panel assumes $\tau=1$ ). 
mium decreases and enrollment shifts. For example, the combined gold and platinum tiers' market share declines 1.9 percentage points in the Base setting when inertia is eliminated, but only 0.5 percentage points in this setting.

Next, consider the effect of removing market power alone (i.e., with inertia and with risk adjustment). As expected, removing market power decreases premiums in all metal tiers (Figure 4, panel a) and increases enrollment in the market (Figure 3, panel b). The premium decreases vary significantly within metal tiers depending on which plans have higher markups in the Base setting. Because some silver and platinum plans have particularly high markups in the Base setting (Figure 4, panel a), consumers sort into these plans and away from bronze plans when market power is removed (Figure 4, panel b). Eliminating inertia then enhances this pattern of consumer substitution from less generous to more generous tiers. The combined gold and platinum market share declines by 1.9 percentage points in the Base setting, but increases by 4.6 percentage points in the setting without market power. Given that the more generous tiers are adversely selected, this increase in market share leads to further decreases in premiums (Figure 4, panel a) and claims (Figure 4, panel c) in the gold and platinum tiers. On net, eliminating inertia without firm market power has a minimal impact on average premiums because it shifts demand towards cheaper plans within the more expensive gold and platinum tiers.

Given the very different interactions risk adjustment and market power have with inertia on their own, we would expect eliminating inertia without risk adjustment or market power to have an intermediate effect on premiums. Indeed, premiums decline in all metal tiers when both risk adjustment and market power are removed, but the gradient in premiums across metal tiers is considerably steeper (Figure 4, panel a). Consequently, the enrollment shifts associated with eliminating risk adjustment alone and market power alone are both present when risk adjustment and market power are removed. Bronze plan market share expands, but so does gold and platinum market share. Eliminating inertia enhances these demand shifts. Hence, eliminating inertia without risk adjustment and market power has a smaller impact on average premiums than in the setting without risk adjustment, but a larger impact than in the setting without market power. ${ }^{20}$

Eliminating inertia has the largest impact on social welfare in the Base setting. The top panel of Figure 5 indicates that when inertia is eliminated, per-capita social welfare increases $\$ 902$ in the Base setting, compared to $\$ 658$ in the absence of risk adjustment, $\$ 547$ in the absence of mar-

\footnotetext{
${ }^{20}$ Appendix Table A5 provides further insight into this phenomenon; when inertia is removed in a scenario without market power, consumer sorting into lower-cost plans within metal tier causes monthly premiums to decrease by $\$ 38$ in the platinum tier if risk adjustment is applied, but by $\$ 74$ in the platinum tier if risk adjustment is not applied. Adverse selection across metal tiers then causes platinum premiums to rise by $\$ 15$ if risk adjustment is applied, and by $\$ 67$ if risk adjustment is not applied.
} 
ket power, and $\$ 250$ in the absence of both market power and risk adjustment. Consumer surplus changes are similar in all four settings, in part because the ACA's endogenous subsidies shield consumers from premium changes. However, taxpayers fare far worse in the counterfactual settings because the average premium reductions are smaller than in the Base setting, resulting in substantially smaller reductions in government subsidy spending. In fact, government subsidy spending slightly increases in the setting where both risk adjustment and market power are eliminated because of an increase in silver plan premiums (recall that the ACA's endogenous subsidy is tied to the second-cheapest silver plan premium).

In the bottom panel of Figure 5, eliminating inertia is much less likely to be welfare-improving. For example, in contrast to the Base scenario, eliminating inertia in a setting without risk adjustment and market power would result in a negative welfare impact if only about $25 \%$ of inertia represents a true switching cost. In this setting, removing inertia would reduce welfare by $\$ 709$ if all of inertia were a true switching cost. Thus, there are settings in which "nudging would hurt" in the California exchange as in Handel (2013)'s analysis of employer-based health insurance. This sensitivity exercise demonstrates that the ranking of inertia's impact on social welfare is preserved for all values of $\tau$. Eliminating inertia in the Base setting has the largest welfare benefit if inertia is purely a behavioral error and the smallest welfare cost if inertia is a true switching cost.

\subsection{Simulation Results: Inertia Interactions with Subsidy Design, Consumer Churn, and Provider Networks}

Finally, we explore how several policy-driven features of the ACA environment interact with inertia. First, we convert the ACA's endogenous, price-linked subsidy to an exogenous subsidy or voucher. Second, we eliminate churn in exchange eligibility. Third, we evaluate the impact of provider networks on inertia by removing only the part of inertia not driven by provider network inclusivity. The results are presented in Figure 6.

Eliminating inertia when subsidies are set exogenously at the observed ACA subsidy has a smaller overall impact than in the Base setting where subsidies are endogenous. ${ }^{21}$ This is because switching from endogenous subsidies to exogenous subsidies already reduces firm market power. Converting the ACA's endogenous subsidy to an exogenous subsidy reduces average premiums by $\$ 2$ per month. This premium decrease would be significantly larger in a market with less competition than in the California exchange, particularly if only one firm participated and could exert full control over the benchmark premium; see, e.g., Jaffe and Shepard (2020). With exogenous subsi-

\footnotetext{
${ }^{21}$ See Appendix Tables A6 and A7 for dollar values.
} 
dies, average premiums fall by $8.7 \%$ (panel a) and exchange coverage falls by $1.3 \%$ (panel b) when inertia is eliminated. The reduction in coverage is less than half of the $3.1 \%$ reduction in the Base setting. The elimination of inertia is more beneficial for consumers with an exogenous subsidy because consumers fully benefit from premium savings associated with switching plans (panel c). Conversely, government spending is largely unchanged when we remove inertia because subsidy levels are fixed. Annual per-capita social welfare increases by only $\$ 532$, compared with $\$ 902$ in the Base setting.

Eliminating inertia in a market without churn has a larger impact than in the Base setting where churn is significant. ${ }^{22}$ This is because eliminating eligibility churn increases the proportion of inertial enrollees over whom incumbent insurers have greater market power; on its own, eliminating churn causes average premiums to increase from $\$ 442$ to $\$ 451$ (panel a). Eliminating inertia without churn reduces average premiums by $16.8 \%$, compared with $13.2 \%$ in the Base setting. The $4.5 \%$ reduction in coverage is more than $30 \%$ larger than the $3.1 \%$ reduction in the Base setting (panel b). Consumers who churn in the Base setting are more premium-sensitive and have weaker preferences for insurance. Annual per-capita social welfare increases by $\$ 965$ (panel c), which is slightly larger than the $\$ 902$ increase in the Base setting. These simulation results indicate that high consumer churn in the ACA exchanges mitigates some of the impact of inertia.

In our final analysis, we investigate whether consumer attachment to a plan's provider network could be a key mechanism driving the impact of inertia in the ACA exchanges. ${ }^{23}$ Attachment to a provider network could be a key driver if there are hassle costs, health costs, or other costs associated with disrupting relationships with providers once established (Drake et al., 2021; Sabety, 2021). Appendix Table A8 indicates that network breadth has only a minimal effect on plan choice, but network inclusivity has a statistically significant and negative impact on plan choice. For example, a standard deviation increase in the network breadth of an enrollee's lagged plan (13.6\%) is valued equivalently to a $\$ 0.02$ increase in monthly premiums, but a standard deviation increase in the network inclusivity of an enrollee's lagged plan (14.8\%) is valued equivalently to a $\$ 8.34$ decrease in monthly premiums. Inertia is therefore smaller when a plan's network has more in common with other plan networks and larger when the network contains more exclusive providers. These effects are too small to affect our simulation results. Figure 6 indicates that eliminating inertia except for the part due to network attachment has a similar impact on premiums, enrollment, and welfare as eliminating all inertia in the Base setting. Hence, network preferences do not appear to be a key mechanism driving the welfare impact of inertia.

\footnotetext{
${ }^{22}$ See Appendix Tables A6 and A7 for dollar values.

${ }^{23}$ See Appendix Table A9 for dollar values.
} 
Figure 6: Equilibrium Impacts of Inertia's Interactions with Subsidy Design, Consumer Churn, and Provider Networks

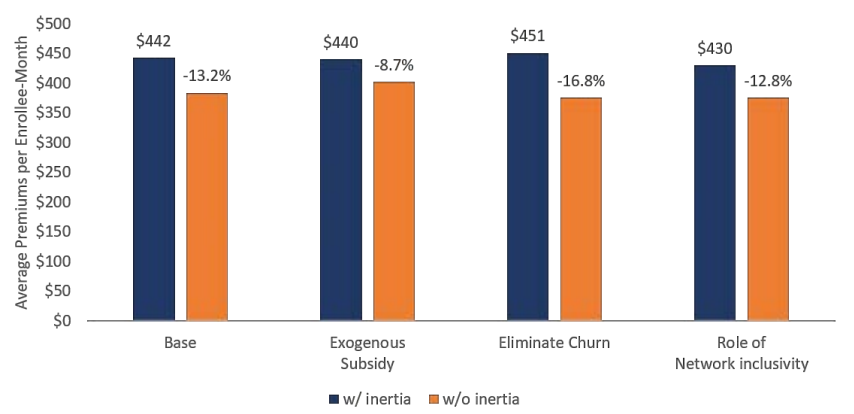

(a) Average Premiums

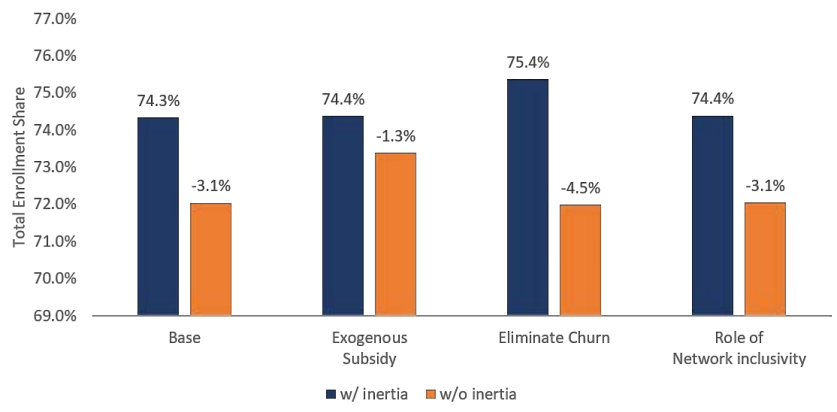

(b) Enrollment Share

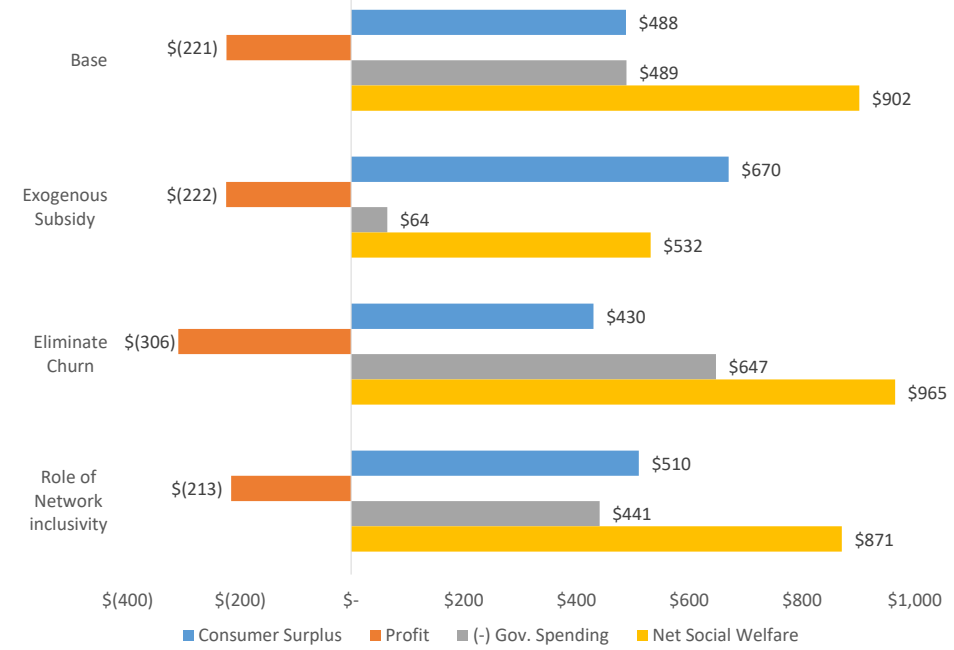

(c) Change in Consumer Surplus, Profit, Government Spending, and Social Welfare

Notes: Figure reports the impact of inertia on average premiums (panel a), share of eligible consumers enrolled in an exchange plan (panel b), and social welfare (panel c) by simulated setting. The base setting corresponds to the ACA where firms have market power and risk adjustment is in place. Three modifications to the base setting are considered, including: (1) make subsidy exogenous; (2) eliminate churn; and (3) consider the role of provider network inclusivity. The third modified setting compares a reestimated base model with inertia that includes an interaction term between the lagged choice and network inclusivity, with a scenario where inertia is eliminated except for the portion linked to network inclusivity. 


\section{Conclusion}

The provision of health insurance in the U.S. relies heavily on managed competition markets. The goal of managed competition is to encourage private firms to compete and offer high-quality, lowcost benefits to consumers. In this paper, we present new evidence on how consumer choice frictions dampen firm competition in an important environment: the California ACA health insurance exchange. We also illustrate how the fairly intricate policy choices common to managed competition markets can amplify or mitigate these effects.

The choice friction of interest in this paper is inertia, the tendency of consumers not to switch product choices over time even when other products become preferable. We present three novel sets of results regarding inertia in the ACA environment. First, we find high average annual per-capita switching costs of $\$ 2,324$, or $44 \%$ of average premiums, and we estimate that the elimination of these switching costs would reduce average premiums by $13.2 \%$. These results indicate that inertia is a significant source of firm market power. The premium decreases benefit consumers and the government through reduced subsidy spending, increasing annual per-capita welfare by $\$ 902$.

Second, we observe a substantially smaller impact from eliminating inertia on average premiums and social welfare when firm market power and/or risk adjustment are removed. Eliminating inertia in the absence of market power increases consumer surplus by allowing consumers to switch into better plans. However, the net impact on social welfare is smaller than in the ACA setting because government subsidy reductions are small (due to the minimal change in premiums) and firm profit is unaffected (by construction). Removing risk adjustment on its own nearly leads to unraveling of the most generous gold and platinum plan tiers. Eliminating inertia in this setting therefore has a smaller incremental impact on consumer surplus, firm profit, and government spending than in the ACA setting because the market for generous coverage has already largely collapsed.

Third, we analyze several channels through which the effects of inertia are sensitive to policy. Eliminating inertia has a smaller role to play in mitigating market power if premium subsidies are converted to vouchers, but has a larger impact if churn in the exchanges is reduced (e.g., through changes to subsidy eligibility rules or the enactment of a BHP program). The impact of inertia is not sensitive to provider network generosity.

Our study results support the case for reducing choice frictions in the ACA exchanges, particularly in highly-concentrated markets where insurers have considerable market power. However, a primary limitation of our analysis is that we do not identify the economic mechanisms underlying inertia. Thus, we cannot quantify the potentially variable effects of diverse policies intended to reduce inertia. This is currently an active area of research complementary to our own (Brot-Goldberg 
et al., 2021; Domurat et al., 2021; Drake et al., 2021; Kling et al., 2012). Of particular interest are policies that may reduce switching frictions while encouraging enrollees to remain insured, particularly in light of the ACA's central goal of expanding affordable health insurance coverage to the substantial uninsured population. We find that removing inertia would lead to a small increase in the rate of uninsurance. If one takes our model at face value, this is optimal from a social welfare perspective. However, inertia may not be the only choice friction at work in the ACA or other insurance markets (Abaluck and Gruber, 2011; Handel and Kolstad, 2015). If other frictions exist that lead consumers to place too little weight on the mortality consequences of their insurance choices (Abaluck et al., 2021), then our model parameters may not fully reflect the impact of reductions in insurance on welfare. ${ }^{24}$

In spite of these limitations, our paper offers novel evidence on the predicted consequences of removing inertia for premiums, government spending, and enrollment in an important new marketplace. Our paper also offers a tractable framework for evaluating those consequences as further evidence develops on the mechanisms underlying inertia, and as new managed competition policies are developed and tested.

\section{References}

Abaluck, J. and A. Adams (2018, May). What do consumers consider before they choose? identification from asymmetric demand responses. Conditionally accepted at The Quarterly Journal of Economics.

Abaluck, J., M. Caceres Bravo, P. Hull, and A. Starc (2021, March). Mortality effects and choice across private health insurance plans. Forthcoming, Quarterly Journal of Economics.

Abaluck, J. and J. Gruber (2011). Choice inconsistencies among the elderly: Evidence from plan choice in the medicare part d program. The American Economic Review 101(4), 1180-1210.

Abaluck, J. and J. Gruber (2016). Evolving choice inconsistencies in choice of prescription drug insurance. American Economic Review 106(8), 2145-2184.

Abraham, J., C. Drake, D. Sacks, and K. Simon (2017). Demand for health insurance marketplace plans was highly elastic in 2014-2015. Economics Letters 159, 69-73.

Aizawa, N. and Y. S. Kim (2018). Advertising and risk selection in health insurance markets. American Economic Review 108(3), 828-867.

\footnotetext{
${ }^{24}$ For recent research on the mortality effects of being insured or being more generously insured, see, e.g., Chandra et al. (2021), Goldin et al. (2021), Miller et al. (2021), and review in Sommers et al. (2017).
} 
Bhargava, S., G. Loewenstein, and J. Sydnor (2017). Choose to lose: Health plan choices from a menu with dominated options. Quarterly Journal of Economics, 1319-1372.

Brot-Goldberg, Z., T. Layton, B. Vabson, and A. Y. Wang (2021, January). The behavioral foundations of default effects: Theory and evidence from medicare part d. NBER Working Paper No. 28331.

Cebul, R. D., J. B. Rebitzer, L. J. Taylor, and M. E. Votruba (2011). Unhealthy insurance markets: Search frictions and the cost and quality of health insurance. American Economic Review 101(5), $1842-71$.

Centers for Medicare and Medicaid Services (2018, January). National Health Expentire Data. https://www.cms.gov/Research-Statistics-Data-and-Systems/ Statistics-Trends-and-Reports/NationalHealthExpendData/

NationalHealthAccountsHistorical.html.

Chandra, A., E. Flack, and Z. Obermeyer (2021, February). The health costs of cost-sharing. Working paper.

Coughlin, T., J. Holahan, K. Caswell, and M. McGrath (2014, May). Uncompensated Care for Uninsured in 2013: A Detailed Examination. https://kaiserfamilyfoundation.files. wordpress.com/2014/05/8596-uncompensated-care-for-the-uninsured-in-2013. pdf.

Curto, V., L. Einav, J. Levin, and J. Bhattacharya (2020, June). Can health insurance competition work? evidence from medicare advantage. Accepted, Journal of Political Economy.

Cutler, D. and S. Reber (1998). Paying for health insurance: the trade-off between competition and adverse selection. Quarterly Journal of Economics 113(2), 433-466.

Dafny, L. (2015, November). Evaluating the impact of health insurance industry consolidation: Learning from experience. Commonwealth Fund pub. 1845.

Decarolis, F., M. Polyakova, and S. Ryan (2020, May). Subsidy design in privately provided social insurance: Lessons from medicare part d. Journal of Political Economy 128(5).

Department of Managed Health Care (2016). Premium Rate Review Filings. http://wpso . dmhc . ca.gov/ratereview/.

Diamond, R., M. J. Dickstein, T. McQuade, P. P. R. Diamond, M. J. Dickstein, T. McQuade, and P. Persson (2021, March). Insurance without commitment: Evidence from the aca marketplaces. Working paper.

Domurat, R. (2018). How do supply-side regulations in the aca impact market outcomes? evidence from california. UCLA Working Paper. 
Domurat, R., I. Menashe, and W. Yin (2021). The role of behavioral frictions in health insurance marketplace enrollment and risk: Evidence from a field experiment. American Economic Review 111(5), 1549-1574.

Drake, C. (2019). What are consumers willing to pay for a broad network health plan?: Evidence from covered california. Journal of Health Economics 65, 63-67.

Drake, C., C. Ryan, and B. E. Dowd (2021, March). Sources of inertia in health plan choice in the individual health insurance market. Available at SSRN: https://ssrn.com/abstract=3556857.

Dube, J.-P., G. J. Hitsch, and P. E. Rossi (2009). Do switching costs make markets less competitive? Journal of Marketing Research 46(4), 435-45.

Einav, L., A. Finkelstein, and P. Tebaldi (2019, March). Market design in regulated health insurance markets: Risk adjustment vs. subsidies. Working paper.

Einav, L. and J. Levin (2015). Managed competition in health insurance. Journal of the European Economic Association 13(6), 998-1021.

Enthoven, A. (1993). The history and principles of managed competition. Health Affairs 34(1), $24-48$.

Ericson, K. (2014). Consumer inertia and firm pricing in the medicare part d prescription drug insurance exchange. American Economic Journal: Economic Policy 6(1), 38-64.

Ericson, K. and A. Starc (2015). Pricing regulation and imperfect competition on the massachusetts health insurance exchange. Review of Economics and Statistics 97(3), 667-682.

Ericson, K. and A. Starc (2016). How product standardization affects choice: Evidence from the massachusetts health insurance exchange. Journal of Health Economics 50, 71-85.

Farrell, J. and P. Klemperer (2007). Coordination and Lock-In: Competition with Switching Costs and Network Effects, Volume 3 of Handbook of Industrial Organization. Amsterdam: NorthHolland.

Fleitas, S. (2017, May). Dynamic competition and price regulation when consumers have inertia: Evidence from medicare part d. Working paper.

Geruso, M., T. Layton, G. McCormack, and M. Shepard (2019, September). The two margin problem in insurance markets. Conditionally accepted at The Review of Economics and Statistics.

Goldin, J., I. Z. Lurie, and J. McCubbin (2021, February). Health insurance and mortality: Experimental evidence from taxpayer outreach. Quarterly Journal of Economics 136(1), 1-49.

Graves, J. A., L. Nshuti, J. Everson, M. Richards, M. Buntin, S. Nikpay, Z. Zhou, and D. Polsky (2020). Breadth and exclusivity of hospital and physician networks in us insurance markets. JAMA Network Open 3(12). 
Hackmann, M., J. Kolstad, and A. Kowalski (2015, March). Adverse selection and an individual mandate: When theory meets practice. The American Economic Review 105(3), 1030-1066.

Handel, B. (2013). Adverse selection and inertia in health insurance markets: When nudging hurts. The American Economic Review 103(7), 2643-2682.

Handel, B. and J. Kolstad (2015). Health insurance for "humans": Information frictions, plan choice, and consumer welfare. American Economic Review 105(8), 2449-2500.

Handel, B. R. and J. Schwartzstein (2018). Frictions or mental gaps: What's behind the information we (don't) use and when do we care? Journal of Economic Perspectives 32(1), 155-178.

Hausman, J. and J. Poterba (1987). Household behavior and the tax reform act of 1986. Journal of Economic Perspectives 1(1), 101-119.

Heiss, F., D. McFadden, J. Winter, A. Wupperman, and B. Zhou (2016, October). Inattention and switching costs as sources of inertia in medicare part d. NBER Working Paper 22765.

Ho, K., J. Hogan, and F. Scott Morton (2017). The impact of consumer inattention on insurer pricing in the medicare part d program. The RAND Journal of Economics 48(4), 877-905.

Hortacsu, A., S. A. Madanizadeh, and S. L. Puller (2017). Power to choose? an analysis of consumer inertia in the residential electricity market. American Economic Journal: Economic Policy 9(4), 192-226.

Jaffe, S. and M. Shepard (2020). Price-linked subsidies and imperfect competition in health insurance. American Economic Journal: Economic Policy 12(3), 279-311.

Kaiser Family Foundation (2020). State health facts: Health reform. https://www.kff.org/statecategory/health-reform/health-insurance-marketplaces/.

Ketcham, J., C. Lucarelli, and C. Power (2015). Paying attention or paying too much in medicare part d. American Economic Review 105(1), 204-233.

Kling, J. R., S. Mullainathan, E. Shafir, L. Vermeulen, , and M. V. Wrobel (2012). Comparison friction: Experimental evidence from medicare drug plans. Quarterly Journal of Economics 127(1), 199-235.

Luco, F. (2019). Switching costs and competition in retirement investment. American Economic Journal: Microeconomics 11(2), 26-54.

Mahoney, N. and E. G. Weyl (2017). Imperfect competition in selection markets. The Review of Economics and Statistics 99(4), 637-651.

Miller, K. (2019, June). Estimating costs when consumers have inertia: Are private medicare insurers more efficient? Working paper. 
Miller, K., A. Petrin, R. Town, and M. Chernew (2019, February). Optimal managed competition subsidies. Working paper.

Miller, S., N. Johnson, and L. R. Wherry (2021, January). Medicaid and mortality: New evidence from linked survey and administrative data. Forthcoming, Quarterly Journal of Economics.

Panhans, M. (2019). Adverse selection in aca exchange markets: Evidence from colorado. American Economic Journal: Applied Economics 11(2), 1-36.

Polsky, D., Z. Cidav, and A. Swanson (2016, October). Marketplace plans with narrow physician networks feature lower monthly premiums than plans with larger networks. Health Affairs.

Polyakova, M. (2016). Regulation of insurance with adverse selection and switching costs: Evidence from medicare part d. American Economic Journal: Applied Economics 8(3), 165-195.

Pope, G., H. Bachofer, A. Pearlman, J. Kautter, E. Hunter, D. Miller, and P. Keenan (2014). Risk transfer formula for individual and small group markets under the affordable care act. Medicare and Medicaid Research Review 4(3), 1-46.

Sabety, A. (2021, January). The value of relationships in health care. Working paper.

Saltzman, E. (2019). Demand for health insurance: Evidence from the california and washington aca exchanges. Journal of Health Economics 63, 197-222.

Saltzman, E. (2021). Managing adverse selection: Underinsurance vs. underenrollment. The RAND Journal of Economics 52(2), 359-381.

Sen, A. P. and T. DeLeire (2018). How does expansion of public health insurance affect risk pools and premiums in the market for private health insurance? evidence from medicaid and the affordable care act marketplaces. Health Economics 27, 1877-1903.

Shepard, M. (2016). Hospital network competition and adverse selection: Evidence from the massachusetts health insurance exchange. The National Bureau of Economic Research.

Sommers, B. D., A. A. Gawande, and K. Baicker (2017). Health insurance coverage and health what the recent evidence tells us. New England Journal of Medicine 377, 586-593.

Starc, A. (2014). Insurer pricing and consumer welfare: Evidence from medigap. RAND Journal of Economics 45(1), 198-220.

Tebaldi, P. (2020, January). Estimating equilibrium in health insurance exchanges: Price competition and subsidy design under the aca. Working paper.

Train, K. (2009). Discrete Choice Methods with Simulation. Cambridge: Cambridge University Press.

U.S. Census Bureau (2019, August). Survey of Income and Program Participation. https: //www . census.gov/sipp/. 
ELECTRONIC APPENDICES - NOT FOR PRINT PUBLICATION 


\section{A Constructing the Outside Option}

In this study, we use five years of administrative longitudinal data on exchange enrollees. Previous studies of the California exchange treat demand as static and construct the outside option by merging the administrative data with survey data on the uninsured from sources such as the American Community Survey (ACS) or Current Population Survey (CPS) (Tebaldi, 2020; Domurat, 2018; Saltzman, 2019). Our focus is on switching between plans and transitions between exchange plans and other options (i.e., no insurance or exiting the market for another insurance option). Hence, we construct the outside option population using enrollees in our administrative data for years in which they were not enrolled in an exchange plan, subject to remaining eligible for exchange coverage. For example, a consumer that appears in our administrative data in 2016 and 2017 would be deemed uninsured in 2014, 2015, and 2018, subject to remaining eligible for exchange coverage.

In our administrative data, we do not observe whether consumers become uninsured or become ineligible for exchange coverage in years that they do not appear. We impute eligibility for exchange coverage using data from the U.S. Census Bureau's Survey of Income and Program Participation (SIPP) (U.S. Census Bureau, 2019). The SIPP is a panel data set that asks respondents their insurance status during each month. The SIPP also asks respondents why they may have changed coverage status. Potential reasons include obtaining or losing an offer of employer-provided insurance, moving into or out of the state, or becoming eligible for public insurance such as Medicare or Medicaid. To conduct the imputation, we first identify SIPP respondents who transitioned into or out of the individual market. For these respondents, we then construct a transitioned variable indicating whether the respondent became newly eligible or ineligible for the individual market. This variable equals 1 if at least one of the following criteria are met: (1) the respondent is a member of a household that lost or gained an employer-sponsored insurance offer; (2) the respondent moved into or out of California; (3) the respondent experienced a drop in income that made him or her eligible for Medicaid; and (4) the respondent turned 65 and became eligible for Medicare. We estimate a binomial logit model that regresses the transitioned variable on observable demographic characteristics available in both the SIPP and the administrative data, including age, gender, race, income and size of household. We then used the estimated logit to perform an out-of-sample prediction of the probability of exchange eligibility in our administrative data. If this probability exceeded a random draw from the uniform distribution on the interval $(0,1)$, then the consumer was flagged as exchange eligible. We remove from our outside option population any consumer-year combinations that correspond to years during which the consumer was predicted to be ineligible for exchange coverage. For the example consumer above, the logit prediction would be used to 
determine if the consumer transitioned into or out of the market and was therefore ineligible for exchange coverage in 2014, 2015, and 2018. 


\section{B Mathematical Formulas in the ACA Exchange Model}

In this appendix, we write the model variables in terms of three variables: (1) the household choice probabilities $q_{i j t}\left(\mathbf{p}_{t}\right)$; (2) the risk scores $r_{j m t}\left(\mathbf{p}_{t}\right)$; and (3) plan average claims $c_{j m t}\left(\mathbf{p}_{t}\right)$. Marginal revenue $M R_{j m t}\left(\mathbf{p}_{t}\right)$, marginal claims $M C_{j m t}\left(\mathbf{p}_{t}\right)$, marginal transfer $M R A_{j m t}\left(\mathbf{p}_{t}\right)$, and marginal variable administrative cost $M V_{j t}\left(\mathbf{p}_{t}\right)$ can be expressed as

$$
\begin{gathered}
M R_{j m t}\left(\mathbf{p}_{t}\right)=\left(\frac{\partial q_{j m t}\left(\mathbf{p}_{t}\right)}{\partial p_{j m t}}\right)^{-1} \sum_{i \in I, k \in J_{f m t}} \sigma_{i t}\left(q_{i j t}\left(\mathbf{p}_{t}\right)+p_{k m t} \frac{\partial q_{i k t}\left(\mathbf{p}_{t}\right)}{\partial p_{j m t}}\right) \\
M C_{j m t}\left(\mathbf{p}_{t}\right)=\left(\frac{\partial q_{j m t}\left(\mathbf{p}_{t}\right)}{\partial p_{j m t}}\right)^{-1} \sum_{k \in J_{f m t}}\left[c_{k m t}\left(\mathbf{p}_{t}\right) \frac{\partial q_{k m t}\left(\mathbf{p}_{t}\right)}{\partial p_{j m t}}+q_{k m t}\left(\mathbf{p}_{t}\right) \frac{\partial c_{k m t}\left(\mathbf{p}_{t}\right)}{\partial p_{j m t}}\right] \\
M R A_{j m t}\left(\mathbf{p}_{t}\right)=\left(\frac{\partial q_{j m t}\left(\mathbf{p}_{t}\right)}{\partial p_{j m t}}\right)^{-1} \sum_{k \in J_{f m t}}\left[\frac{\partial R_{t}\left(\mathbf{p}_{t}\right)}{\partial p_{j m t}}\left(r s_{k m t}\left(\mathbf{p}_{t}\right)-u s_{k m t}\left(\mathbf{p}_{t}\right)\right)\right. \\
\left.+R_{t}\left(\mathbf{p}_{t}\right)\left(\frac{\partial r s_{k m t}\left(\mathbf{p}_{t}\right)}{\partial p_{j m t}}-\frac{\partial u s_{k m t}\left(\mathbf{p}_{t}\right)}{\partial p_{j m t}}\right)\right] \\
M V_{j t}\left(\mathbf{p}_{t}\right)=v_{f t} \frac{\partial q_{f t}\left(\mathbf{p}_{t}\right) / \partial p_{j m t}}{\partial q_{j m t}\left(\mathbf{p}_{t}\right) / \partial p_{j m t}}
\end{gathered}
$$

where $v_{f t}$ is average variable administrative cost and

$$
\begin{aligned}
\frac{\partial R_{t}\left(\mathbf{p}_{t}\right)}{\partial p_{j m t}}=\sum_{l \in J_{m t}} M R_{l m t}\left(\mathbf{p}_{t}\right) \frac{\partial q_{l m t}\left(\mathbf{p}_{t}\right)}{\partial p_{j m t}} & \left(\sum_{m \in M, l \in J_{m t}} h_{l} q_{l m t}\left(\mathbf{p}_{t}\right)\right)^{-1}\left[h_{k} \frac{\partial q_{k m t}\left(\mathbf{p}_{t}\right)}{\partial p_{j m t}}-\frac{h_{k} q_{k m t}\left(\mathbf{p}_{t}\right)}{\sum_{m \in M, l \in J_{m t}} h_{l} q_{l m t}\left(\mathbf{p}_{t}\right)} \sum_{l \in J_{m t}} h_{l} \frac{\partial q_{l m t}\left(\mathbf{p}_{t}\right)}{\partial p_{j m t}}\right] \\
\frac{\partial r s_{k m t}\left(\mathbf{p}_{t}\right)}{\partial p_{j m t}}= & \left(\sum_{m \in M, l \in J_{m t}} r_{l m t}\left(\mathbf{p}_{t}\right) q_{l m t}\left(\mathbf{p}_{t}\right)\right)^{-1}\left[\left(r_{k m t}\left(\mathbf{p}_{t}\right) \frac{\partial q_{k m t}\left(\mathbf{p}_{t}\right)}{\partial p_{j m t}}+q_{k m t}\left(\mathbf{p}_{t}\right) \frac{\partial r_{k m t}\left(\mathbf{p}_{t}\right)}{\partial p_{j m t}}\right)\right. \\
& \left.-\frac{r_{j m t}\left(\mathbf{p}_{t}\right) q_{j m t}\left(\mathbf{p}_{t}\right)}{\sum_{m \in M, l \in J_{m t}} r_{l m t}\left(\mathbf{p}_{t}\right) q_{l m t}\left(\mathbf{p}_{t}\right)} \sum_{l \in J_{m t}}\left[r_{l m t}\left(\mathbf{p}_{t}\right) \frac{\partial q_{l m t}\left(\mathbf{p}_{t}\right)}{\partial p_{j m t}}+q_{l m t}\left(\mathbf{p}_{t}\right) \frac{\partial r_{l m t}\left(\mathbf{p}_{t}\right)}{\partial p_{j m t}}\right]\right]
\end{aligned}
$$

Given the nested logit error, the $(k, j)$ element of the Jacobian matrix of the household choice probability is

$$
\frac{\partial q_{i k t}\left(\mathbf{p}_{t}\right)}{\partial p_{i j t}}= \begin{cases}\beta_{i}^{p} q_{i j t}\left(\mathbf{p}_{t}\right)\left[\frac{1}{\lambda}+\frac{\lambda-1}{\lambda} q_{i j t}^{\prime}\left(\mathbf{p}_{t}\right)-q_{i j t}\left(\mathbf{p}_{t}\right)\right] & k=j \\ \beta_{i}^{p} q_{i j t}\left(\mathbf{p}_{t}\right)\left[\frac{\lambda-1}{\lambda} q_{i j t}^{\prime}\left(\mathbf{p}_{t}\right)-q_{i j t}\left(\mathbf{p}_{t}\right)\right] & k \neq j\end{cases}
$$

where $q_{i j t}^{\prime}\left(\mathbf{p}_{t}\right)$ is the probability of choosing $j$, conditional on choosing a plan. The $(k, j)$-element of the Jacobian matrix of the plan risk score equals 


$$
\frac{\partial r_{k m t}\left(\mathbf{p}_{t}\right)}{\partial p_{j m t}}=\frac{r_{k m t}\left(\mathbf{p}_{t}\right)}{q_{k m t}\left(\mathbf{p}_{t}\right)} \sum_{d \in D} \gamma^{d}\left[\frac{\partial q_{d k m t}\left(\mathbf{p}_{t}\right)}{\partial p_{j m t}}-s_{d k m t}\left(\mathbf{p}_{t}\right) \frac{\partial q_{k m t}\left(\mathbf{p}_{t}\right)}{\partial p_{j m t}}\right]
$$

The $(k, j)$-element of the Jacobian matrix of plan average claims equals

$$
\frac{\partial c_{k m t}\left(\mathbf{p}_{t}\right)}{\partial p_{j m t}}=\theta^{r} \frac{c_{k m t}\left(\mathbf{p}_{t}\right)}{r_{k m t}\left(\mathbf{p}_{t}\right)} \frac{\partial r_{k m t}\left(\mathbf{p}_{t}\right)}{\partial p_{j m t}}
$$




\section{Detailed Results}

Table A1: Estimated Demand Parameters

\begin{tabular}{|c|c|c|c|c|c|c|c|}
\hline & (1) & (2) & (3) & & (1) & (2) & (3) \\
\hline Monthly Premium $(\$ 100) \times$ & $\begin{array}{c}-0.174^{* * *} \\
(0.002)\end{array}$ & $\begin{array}{c}-0.135^{\text {*** }} \\
(0.002)\end{array}$ & $\begin{array}{c}-0.141^{\text {*** }} \\
(0.002)\end{array}$ & Previous Choice $\times$ & $\begin{array}{c}0.553^{* * *} \\
(0.007)\end{array}$ & $\begin{array}{c}0.231^{* * *} \\
(0.010)\end{array}$ & $\begin{array}{c}0.272^{* * *} \\
(0.011)\end{array}$ \\
\hline $250 \%$ to $400 \%$ of FPL & & $\begin{array}{c}0.039^{* * *} \\
(0.001)\end{array}$ & $\begin{array}{c}0.041^{* * *} \\
(0.001)\end{array}$ & $250 \%$ to $400 \%$ of FPL & & $\begin{array}{c}0.021^{\text {*** }} \\
(0.003)\end{array}$ & $\begin{array}{c}0.023^{* * *} \\
(0.003)\end{array}$ \\
\hline$>400 \%$ of FPL & & $\begin{array}{c}0.082^{* * *} \\
(0.002)\end{array}$ & $\begin{array}{c}0.089^{\text {*** }} \\
(0.002)\end{array}$ & $>400 \%$ of FPL & & $\begin{array}{c}0.036^{* * *} \\
(0.004)\end{array}$ & $\begin{array}{c}0.044^{* * *} \\
(0.004)\end{array}$ \\
\hline Ages 0 to 17 & & $\begin{array}{c}-0.157^{* * *} \\
(0.004)\end{array}$ & $\begin{array}{c}-0.158^{* * *} \\
(0.004)\end{array}$ & Age 0 to 17 & & $\begin{array}{l}-0.008 \\
(0.007)\end{array}$ & $\begin{array}{l}-0.006 \\
(0.007)\end{array}$ \\
\hline Ages 18 to 34 & & $\begin{array}{c}-0.186^{* * *} \\
(0.003)\end{array}$ & $\begin{array}{c}-0.193^{* * *} \\
(0.003)\end{array}$ & Age 18 to 34 & & $\begin{array}{c}-0.009^{* * *} \\
(0.003)\end{array}$ & $\begin{array}{c}-0.009^{* * *} \\
(0.003)\end{array}$ \\
\hline Ages 35 to 54 & & $\begin{array}{c}-0.087^{* * *} \\
(0.002)\end{array}$ & $\begin{array}{c}-0.092^{* * *} \\
(0.002)\end{array}$ & Age 35 to 54 & & $\begin{array}{c}-0.013^{* * *} \\
(0.003)\end{array}$ & $\begin{array}{c}-0.014^{* * *} \\
(0.003)\end{array}$ \\
\hline Black & & $\begin{array}{c}-0.021^{* * *} \\
(0.003)\end{array}$ & $\begin{array}{c}-0.024^{* * *} \\
(0.003)\end{array}$ & Black & & $\begin{array}{c}-0.027^{* * *} \\
(0.008)\end{array}$ & $\begin{array}{c}-0.025^{* * *} \\
(0.009)\end{array}$ \\
\hline Hispanic & & $\begin{array}{c}-0.073^{* * *} \\
(0.002)\end{array}$ & $\begin{array}{c}-0.080^{* * *} \\
(0.002)\end{array}$ & Hispanic & & $\begin{array}{c}-0.027^{* * *} \\
(0.003)\end{array}$ & $\begin{array}{c}-0.032^{* * *} \\
(0.003)\end{array}$ \\
\hline Asian & & $\begin{array}{c}-0.055^{* * *} \\
(0.001)\end{array}$ & $\begin{array}{c}-0.060^{* * *} \\
(0.002)\end{array}$ & Asian & & $\begin{array}{c}-0.052^{* * *} \\
(0.003)\end{array}$ & $\begin{array}{c}-0.053^{* * *} \\
(0.003)\end{array}$ \\
\hline Other race & & $\begin{array}{c}-0.006^{* * *} \\
(0.002)\end{array}$ & $\begin{array}{c}-0.008^{* * *} \\
(0.002)\end{array}$ & Other race & & $\begin{array}{c}-0.017^{\text {*** }} \\
(0.004)\end{array}$ & $\begin{array}{c}-0.019^{* * *} \\
(0.005)\end{array}$ \\
\hline Male & & $\begin{array}{c}-0.021^{* * *} \\
(0.001)\end{array}$ & $\begin{array}{c}-0.023^{\text {*** }} \\
(0.001)\end{array}$ & Male & & $\begin{array}{c}0.026^{* * *} \\
(0.003)\end{array}$ & $\begin{array}{c}0.029^{* * *} \\
(0.003)\end{array}$ \\
\hline Family & & $\begin{array}{l}-0.001 \\
(0.001)\end{array}$ & $\begin{array}{c}0.000 \\
(0.001)\end{array}$ & Family & & $\begin{array}{c}-0.044^{* * *} \\
(0.002)\end{array}$ & $\begin{array}{c}-0.050^{* * *} \\
(0.002)\end{array}$ \\
\hline$\overline{\mathrm{AV}}$ & $\begin{array}{c}0.591^{* * *} \\
(0.007)\end{array}$ & $\begin{array}{c}0.817^{* * *} \\
(0.010)\end{array}$ & $\begin{array}{c}0.838^{* * *} \\
(0.010)\end{array}$ & Anthem & & $\begin{array}{c}0.121^{* * *} \\
(0.007)\end{array}$ & $\begin{array}{c}0.111^{* * *} \\
(0.007)\end{array}$ \\
\hline Silver & $\begin{array}{c}0.122^{* * *} \\
(0.002)\end{array}$ & $\begin{array}{c}0.134^{* * * *} \\
(0.002)\end{array}$ & $\begin{array}{c}0.148^{* * *} \\
(0.002)\end{array}$ & Blue Shield & & $\begin{array}{c}0.217^{* * *} \\
(0.007)\end{array}$ & $\begin{array}{c}0.208^{* * *} \\
(0.008)\end{array}$ \\
\hline HMO & $\begin{array}{c}-0.014^{* * *} \\
(0.001)\end{array}$ & $\begin{array}{c}-0.034^{* * *} \\
(0.001)\end{array}$ & $\begin{array}{c}-0.073^{* * *} \\
(0.002)\end{array}$ & Kaiser & & $\begin{array}{c}0.054^{* * *} \\
(0.004)\end{array}$ & $\begin{array}{c}0.060^{* * *} \\
(0.004)\end{array}$ \\
\hline Anthem & $\begin{array}{c}0.078^{* * *} \\
(0.002)\end{array}$ & $\begin{array}{c}0.092^{* * *} \\
(0.002)\end{array}$ & $\begin{array}{c}0.305^{* * *} \\
(0.009)\end{array}$ & Health Net & & $\begin{array}{c}0.028^{* * *} \\
(0.004)\end{array}$ & $\begin{array}{c}0.032^{* * *} \\
(0.004)\end{array}$ \\
\hline Blue Shield & $\begin{array}{c}0.097^{* * *} \\
(0.002)\end{array}$ & $\begin{array}{c}0.103^{* * *} \\
(0.002)\end{array}$ & $\begin{array}{c}0.222^{* * * *} \\
(0.008)\end{array}$ & HMO & & $\begin{array}{c}0.145^{* * *} \\
(0.006)\end{array}$ & $\begin{array}{c}0.141^{* * *} \\
(0.007)\end{array}$ \\
\hline Kaiser & $\begin{array}{c}0.116^{* * *} \\
(0.002)\end{array}$ & $\begin{array}{c}0.138^{* * *} \\
(0.002)\end{array}$ & $\begin{array}{c}0.057^{\text {*** }} \\
(0.005)\end{array}$ & $\mathrm{AV}$ & & $\begin{array}{c}0.397^{* * *} \\
(0.011)\end{array}$ & $\begin{array}{c}0.420^{* * *} \\
(0.012)\end{array}$ \\
\hline Health Net & $\begin{array}{c}0.020^{* * *} \\
(0.001)\end{array}$ & $\begin{array}{c}0.022^{* * *} \\
(0.001)\end{array}$ & $\begin{array}{c}-0.146^{* * *} \\
(0.010)\end{array}$ & Silver & & $\begin{array}{c}-0.181^{* * *} \\
(0.003)\end{array}$ & $\begin{array}{c}-0.199^{* * *} \\
(0.004)\end{array}$ \\
\hline Anthem $x$ HMO & $\begin{array}{c}-0.170^{* * *} \\
(0.003)\end{array}$ & $\begin{array}{c}-0.179^{* * *} \\
(0.004)\end{array}$ & $\begin{array}{c}-0.130^{* * *} \\
(0.003)\end{array}$ & & & & \\
\hline Nesting Parameter & $\begin{array}{c}0.130^{* * *} \\
(0.002)\end{array}$ & $\begin{array}{c}0.136^{* * *} \\
(0.002)\end{array}$ & $\begin{array}{c}0.148^{* * *} \\
(0.002)\end{array}$ & & & & \\
\hline
\end{tabular}

Notes: Robust standard errors are in parentheses $\left({ }^{* * *}\right.$ indicates statistical significance at the $1 \%$ level, ${ }^{* *}$ at the $5 \%$ level, and ${ }^{*}$ at the $10 \%$ level). Specification is the same as in Table 4 specification (2). 
Table A2: Simulation Results: Premiums, Coverage, and Claims

\begin{tabular}{|c|c|c|c|c|c|c|c|c|c|}
\hline & Base & (1) & (2) & (3) & (4) & (5) & (6) & (7) & (8) \\
\hline \multicolumn{10}{|c|}{ Scenario Definitions } \\
\hline Inertia & $\checkmark$ & & & $\checkmark$ & & $\checkmark$ & & $\checkmark$ & \\
\hline Oligopoly & $\checkmark$ & $\mathrm{N} / \mathrm{A}$ & $\checkmark$ & $\checkmark$ & $\checkmark$ & & & & \\
\hline Risk adjustment & $\checkmark$ & $\checkmark$ & $\checkmark$ & & & $\checkmark$ & $\checkmark$ & & \\
\hline Endog. Subsidy & $\checkmark$ & $\checkmark$ & $\checkmark$ & $\checkmark$ & $\checkmark$ & $\checkmark$ & $\checkmark$ & $\checkmark$ & $\checkmark$ \\
\hline Churn & $\checkmark$ & $\checkmark$ & $\checkmark$ & $\checkmark$ & $\checkmark$ & $\checkmark$ & $\checkmark$ & $\checkmark$ & $\checkmark$ \\
\hline \multicolumn{10}{|c|}{ Monthly Premiums (Unsubsidized Unless Otherwise Indicated) } \\
\hline Bronze & $\$ 354$ & $\$ 361$ & $\$ 305$ & $\$ 241$ & $\$ 222$ & $\$ 319$ & $\$ 315$ & $\$ 240$ & $\$ 222$ \\
\hline Silver & $\$ 471$ & $\$ 464$ & $\$ 412$ & $\$ 454$ & $\$ 414$ & $\$ 417$ & $\$ 413$ & $\$ 412$ & $\$ 414$ \\
\hline Gold & $\$ 488$ & $\$ 494$ & $\$ 455$ & $\$ 536$ & $\$ 539$ & $\$ 451$ & $\$ 437$ & $\$ 443$ & $\$ 458$ \\
\hline Platinum & $\$ 540$ & $\$ 538$ & $\$ 500$ & $\$ 1194$ & $\$ 1171$ & $\$ 485$ & $\$ 463$ & $\$ 514$ & $\$ 511$ \\
\hline Anthem & $\$ 483$ & $\$ 468$ & $\$ 405$ & $\$ 411$ & $\$ 346$ & $\$ 432$ & $\$ 414$ & $\$ 431$ & $\$ 437$ \\
\hline Blue Shield & $\$ 473$ & $\$ 466$ & $\$ 419$ & $\$ 426$ & $\$ 386$ & $\$ 431$ & $\$ 429$ & $\$ 441$ & $\$ 438$ \\
\hline Health Net & $\$ 404$ & $\$ 406$ & $\$ 347$ & $\$ 327$ & $\$ 293$ & $\$ 353$ & $\$ 378$ & $\$ 369$ & $\$ 345$ \\
\hline Kaiser & $\$ 446$ & $\$ 448$ & $\$ 391$ & $\$ 362$ & $\$ 318$ & $\$ 389$ & $\$ 388$ & $\$ 362$ & $\$ 370$ \\
\hline Other Insurer & $\$ 388$ & $\$ 396$ & $\$ 345$ & $\$ 302$ & $\$ 288$ & $\$ 361$ & $\$ 358$ & $\$ 336$ & $\$ 297$ \\
\hline HMO & $\$ 422$ & $\$ 425$ & $\$ 369$ & $\$ 348$ & $\$ 315$ & $\$ 374$ & $\$ 378$ & $\$ 356$ & $\$ 347$ \\
\hline PPO & $\$ 473$ & $\$ 461$ & $\$ 406$ & $\$ 396$ & $\$ 342$ & $\$ 429$ & $\$ 424$ & $\$ 439$ & $\$ 420$ \\
\hline Average & $\$ 442$ & $\$ 440$ & $\$ 384$ & $\$ 369$ & $\$ 329$ & $\$ 397$ & $\$ 394$ & $\$ 384$ & $\$ 373$ \\
\hline Subsidized Avg. & $\$ 128$ & $\$ 126$ & $\$ 117$ & $\$ 93$ & $\$ 80$ & $\$ 122$ & $\$ 120$ & $\$ 90$ & $\$ 70$ \\
\hline \multicolumn{10}{|l|}{ Coverage } \\
\hline Total Coverage & $1,756,594$ & $1,697,805$ & $1,702,317$ & $1,768,673$ & $1,716,190$ & $1,771,489$ & $1,712,952$ & $1,805,534$ & $1,761,966$ \\
\hline$\%$ Enrolled & $74.3 \%$ & $71.9 \%$ & $72.0 \%$ & $74.8 \%$ & $72.6 \%$ & $75.0 \%$ & $72.5 \%$ & $76.4 \%$ & $74.6 \%$ \\
\hline Bronze & $27.1 \%$ & $27.9 \%$ & $29.9 \%$ & $40.1 \%$ & $44.2 \%$ & $24.0 \%$ & $23.7 \%$ & $29.1 \%$ & $29.8 \%$ \\
\hline Silver & $62.6 \%$ & $59.9 \%$ & $61.6 \%$ & $58.9 \%$ & $55.3 \%$ & $65.2 \%$ & $60.8 \%$ & $52.7 \%$ & $44.9 \%$ \\
\hline Gold & $6.3 \%$ & $7.7 \%$ & $5.7 \%$ & $1.0 \%$ & $0.5 \%$ & $5.7 \%$ & $8.0 \%$ & $11.8 \%$ & $13.8 \%$ \\
\hline Platinum & $4.0 \%$ & $4.5 \%$ & $2.7 \%$ & $0.0 \%$ & $0.0 \%$ & $5.2 \%$ & $7.4 \%$ & $6.4 \%$ & $11.5 \%$ \\
\hline$\%$ Switching & $0.0 \%$ & $25.9 \%$ & $28.4 \%$ & $13.3 \%$ & $34.4 \%$ & $8.0 \%$ & $32.1 \%$ & $20.0 \%$ & $42.0 \%$ \\
\hline \multicolumn{10}{|l|}{ Monthly Claims } \\
\hline Bronze & $\$ 224$ & $\$ 250$ & $\$ 220$ & $\$ 221$ & $\$ 218$ & $\$ 228$ & $\$ 216$ & $\$ 250$ & $\$ 225$ \\
\hline Silver & $\$ 393$ & $\$ 425$ & $\$ 389$ & $\$ 395$ & $\$ 392$ & $\$ 395$ & $\$ 388$ & $\$ 394$ & $\$ 358$ \\
\hline Gold & $\$ 523$ & $\$ 532$ & $\$ 515$ & $\$ 532$ & $\$ 539$ & $\$ 520$ & $\$ 490$ & $\$ 395$ & $\$ 450$ \\
\hline Platinum & $\$ 751$ & $\$ 761$ & $\$ 732$ & $\$ 1154$ & $\$ 1114$ & $\$ 767$ & $\$ 718$ & $\$ 552$ & $\$ 562$ \\
\hline Average & $\$ 370$ & $\$ 399$ & $\$ 355$ & $\$ 327$ & $\$ 316$ & $\$ 381$ & $\$ 381$ & $\$ 362$ & $\$ 354$ \\
\hline
\end{tabular}

Notes: Table reports the impact on premiums, coverage, and claims for each scenario. The Base (or ACA) column reports the observed premiums and coverage. In scenario (1), we eliminate inertia and allow consumers to choose a new plan, but keep premiums the same as in the Base scenario. In scenarios (2) through (8), we simulate combinations of 3 changes: (1) eliminating inertia; (2) repealing risk adjustment; and (3) changing the market structure from oligopoly to perfect competition. The first panel defines each of the scenarios. The second panel summarizes enrollee-weighted average unsubsidized premiums by metal level, insurer, and plan network type. The bottom two rows of the second panel show overall enrollee-weighted average premiums ("Average") and subsidized average premiums ("Subsidized Avg."). The third panel shows total enrollment, the percentage of consumers enrolled in coverage, and market shares by metal level. The final row of the third panel indicates the percentage of consumers who switched plans from the Base scenario. The fourth panel reports average claims by metal tier and on average across all enrollees. 
Table A3: Simulation Results: Change in Annual Per-Capita Social Welfare

\begin{tabular}{|c|c|c|c|c|c|c|c|c|c|}
\hline & Base & (1) & (2) & (3) & (4) & (5) & (6) & (7) & (8) \\
\hline \multicolumn{10}{|l|}{ Scenario Definitions } \\
\hline Inertia & $\checkmark$ & & & $\checkmark$ & & $\checkmark$ & & $\checkmark$ & \\
\hline Oligopoly & $\checkmark$ & N/A & $\checkmark$ & $\checkmark$ & $\checkmark$ & & & & \\
\hline Risk adjustment & $\checkmark$ & $\checkmark$ & $\checkmark$ & & & $\checkmark$ & $\checkmark$ & & \\
\hline Endog. Subsidy & $\checkmark$ & $\checkmark$ & $\checkmark$ & $\checkmark$ & $\checkmark$ & $\checkmark$ & $\checkmark$ & $\checkmark$ & $\checkmark$ \\
\hline Churn & $\checkmark$ & $\checkmark$ & $\checkmark$ & $\checkmark$ & $\checkmark$ & $\checkmark$ & $\checkmark$ & $\checkmark$ & $\checkmark$ \\
\hline \multicolumn{10}{|l|}{ Welfare Changes } \\
\hline Cons. Surplus & & $\$ 470$ & $\$ 488$ & $\$ 101$ & $\$ 510$ & $\$ 57$ & $\$ 529$ & $\$ 262$ & $\$ 682$ \\
\hline Profit & & $(\$ 12)$ & $(\$ 221)$ & $(\$ 153)$ & $(\$ 299)$ & $(\$ 492)$ & $(\$ 492)$ & $(\$ 492)$ & $(\$ 492)$ \\
\hline \multicolumn{10}{|l|}{ Gov. Spending } \\
\hline Prem. Subsidies & & $(\$ 100)$ & $(\$ 500)$ & $(\$ 333)$ & (\$639) & $(\$ 549)$ & $(\$ 607)$ & $(\$ 227)$ & $(\$ 74)$ \\
\hline CSRs & & $(\$ 23)$ & $(\$ 14)$ & $(\$ 12)$ & $(\$ 35)$ & $\$ 14$ & $(\$ 12)$ & (\$37) & $(\$ 81)$ \\
\hline Penalties & & $\$ 25$ & $\$ 23$ & $(\$ 5)$ & $\$ 18$ & $(\$ 7)$ & $\$ 18$ & $(\$ 21)$ & $(\$ 3)$ \\
\hline Uncomp. Care & & $\$ 52$ & $\$ 49$ & $(\$ 8)$ & $\$ 38$ & $(\$ 13)$ & $\$ 40$ & (\$39) & $\$ 0$ \\
\hline Social Welfare & & $\$ 582$ & $\$ 902$ & $\$ 402$ & $\$ 1060$ & $\$ 267$ & $\$ 814$ & $\$ 136$ & $\$ 386$ \\
\hline
\end{tabular}

Notes: Table reports the change in annual per-capita social welfare for each scenario relative to the Base (or ACA) scenario. In scenario (1), we eliminate inertia and allow consumers to choose a new plan, but keep premiums for each scenario the same as in the Base scenario. In scenarios (2) through (8), we simulate combinations of 3 changes: (1) eliminating inertia; (2) repealing risk adjustment; and (3) changing the market structure from oligopoly to perfect competition. The first panel defines each of the scenarios. The second panel reports the change in annual per-capita consumer surplus, firm profit, government spending (including premium subsidies, cost sharing reductions, individual mandate penalties, and uncompensated care), and total social welfare relative to the Base scenario. 
Table A4: Simulation Results: Sensitivity to Inertia Role in Welfare

\begin{tabular}{|c|c|c|c|c|c|c|c|c|c|}
\hline & Base & (1) & $(2)$ & (3) & (4) & (5) & (6) & (7) & $(8)$ \\
\hline \multicolumn{10}{|c|}{ Scenario Definitions } \\
\hline Inertia & $\checkmark$ & & & $\checkmark$ & & $\checkmark$ & & $\checkmark$ & \\
\hline Oligopoly & $\checkmark$ & N/A & $\checkmark$ & $\checkmark$ & $\checkmark$ & & & & \\
\hline Risk adjustment & $\checkmark$ & $\checkmark$ & $\checkmark$ & & & $\checkmark$ & $\checkmark$ & & \\
\hline Endog. Subsidy & $\checkmark$ & $\checkmark$ & $\checkmark$ & $\checkmark$ & $\checkmark$ & $\checkmark$ & $\checkmark$ & $\checkmark$ & $\checkmark$ \\
\hline Churn & $\checkmark$ & $\checkmark$ & $\checkmark$ & $\checkmark$ & $\checkmark$ & $\checkmark$ & $\checkmark$ & $\checkmark$ & $\checkmark$ \\
\hline \multicolumn{10}{|l|}{ Cons. Surplus } \\
\hline$\tau=1$ & & $\$ 470$ & $\$ 488$ & $\$ 101$ & $\$ 510$ & $\$ 57$ & $\$ 529$ & $\$ 262$ & $\$ 682$ \\
\hline$\tau=0.75$ & & $\$ 194$ & $\$ 211$ & $\$ 72$ & $\$ 233$ & $\$ 60$ & $\$ 253$ & $\$ 226$ & $\$ 405$ \\
\hline$\tau=0.50$ & & $(\$ 83)$ & $(\$ 65)$ & $\$ 42$ & $(\$ 43)$ & $\$ 62$ & $(\$ 23)$ & $\$ 189$ & $\$ 129$ \\
\hline$\tau=0.25$ & & $(\$ 359)$ & $(\$ 341)$ & $\$ 12$ & $(\$ 319)$ & $\$ 65$ & $(\$ 300)$ & $\$ 152$ & $(\$ 147)$ \\
\hline$\tau=0$ & & $(\$ 635)$ & (\$618) & $(\$ 17)$ & $(\$ 596)$ & $\$ 67$ & $(\$ 576)$ & $\$ 116$ & $(\$ 424)$ \\
\hline \multicolumn{10}{|l|}{ Social Welfare } \\
\hline$\tau=1$ & & $\$ 582$ & $\$ 902$ & $\$ 402$ & $\$ 1060$ & $\$ 267$ & $\$ 814$ & $\$ 136$ & $\$ 386$ \\
\hline$\tau=0.75$ & & $\$ 306$ & $\$ 625$ & $\$ 372$ & $\$ 783$ & $\$ 269$ & $\$ 538$ & $\$ 100$ & $\$ 110$ \\
\hline$\tau=0.50$ & & $\$ 30$ & $\$ 349$ & $\$ 342$ & $\$ 507$ & $\$ 272$ & $\$ 261$ & $\$ 63$ & $(\$ 166)$ \\
\hline$\tau=0.25$ & & $(\$ 247)$ & $\$ 73$ & $\$ 313$ & $\$ 231$ & $\$ 274$ & $(\$ 15)$ & $\$ 26$ & $(\$ 443)$ \\
\hline$\tau=0$ & & $(\$ 523)$ & $(\$ 204)$ & $\$ 283$ & $(\$ 45)$ & $\$ 276$ & $(\$ 291)$ & $(\$ 10)$ & $(\$ 719)$ \\
\hline
\end{tabular}

Notes: Table reports the sensitivity (as measured by the percentage of inertia $\tau$ that is considered to be a choice error) of the change in annual per-capita consumer surplus and social welfare for each scenario relative to the Base (or ACA) scenario. In scenario (1), we eliminate inertia and allow consumers to choose a new plan, but keep premiums for each scenario the same as in the Base scenario. In scenarios (2) through (8), we simulate combinations of 3 changes: (1) eliminating inertia; (2) repealing risk adjustment; and (3) changing the market structure from oligopoly to perfect competition. The first panel defines each of the scenarios. The second and third panels report the change in annual per-capita consumer surplus and social welfare, respectively, relative to the Base scenario. 
Table A5: Effect of Consumer Sorting on Average Premiums

\begin{tabular}{|c|c|c|c|c|c|c|c|c|c|}
\hline & Base & (1) & (2) & (3) & (4) & (5) & (6) & (7) & (8) \\
\hline \multicolumn{10}{|c|}{ Scenario Definitions } \\
\hline Inertia & $\checkmark$ & & & $\checkmark$ & & $\checkmark$ & & $\checkmark$ & \\
\hline Oligopoly & $\checkmark$ & N/A & $\checkmark$ & $\checkmark$ & $\checkmark$ & & & & \\
\hline Risk adjustment & $\checkmark$ & $\checkmark$ & $\checkmark$ & & & $\checkmark$ & $\checkmark$ & & \\
\hline \multicolumn{10}{|l|}{ No Sorting } \\
\hline Bronze & $\$ 354$ & $\$ 354$ & $\$ 300$ & $\$ 245$ & $\$ 219$ & $\$ 324$ & $\$ 318$ & $\$ 249$ & $\$ 229$ \\
\hline Silver & $\$ 471$ & $\$ 471$ & $\$ 420$ & $\$ 460$ & $\$ 425$ & $\$ 420$ & $\$ 426$ & $\$ 498$ & $\$ 520$ \\
\hline Gold & $\$ 488$ & $\$ 488$ & $\$ 467$ & $\$ 766$ & $\$ 755$ & $\$ 471$ & $\$ 460$ & $\$ 460$ & $\$ 454$ \\
\hline Platinum & $\$ 540$ & $\$ 540$ & $\$ 544$ & $\$ 1505$ & $\$ 1257$ & $\$ 486$ & $\$ 488$ & $\$ 525$ & $\$ 520$ \\
\hline Average & $\$ 442$ & $\$ 442$ & $\$ 394$ & $\$ 460$ & $\$ 421$ & $\$ 399$ & $\$ 400$ & $\$ 427$ & $\$ 435$ \\
\hline \multicolumn{10}{|c|}{ Sorting within metal } \\
\hline Bronze & $\$ 354$ & $\$ 358$ & $\$ 303$ & $\$ 249$ & $\$ 230$ & $\$ 319$ & $\$ 314$ & $\$ 250$ & $\$ 239$ \\
\hline Silver & $\$ 471$ & $\$ 468$ & $\$ 416$ & $\$ 450$ & $\$ 410$ & $\$ 418$ & $\$ 418$ & $\$ 443$ & $\$ 421$ \\
\hline Gold & $\$ 488$ & $\$ 483$ & $\$ 452$ & $\$ 654$ & $\$ 613$ & $\$ 457$ & $\$ 435$ & $\$ 420$ & $\$ 415$ \\
\hline Platinum & $\$ 540$ & $\$ 532$ & $\$ 512$ & $\$ 1156$ & $\$ 1154$ & $\$ 479$ & $\$ 450$ & $\$ 492$ & $\$ 446$ \\
\hline Average & $\$ 442$ & $\$ 441$ & $\$ 391$ & $\$ 434$ & $\$ 402$ & $\$ 395$ & $\$ 391$ & $\$ 389$ & $\$ 371$ \\
\hline \multicolumn{10}{|c|}{ Sorting within exchange } \\
\hline Bronze & $\$ 354$ & $\$ 362$ & $\$ 306$ & $\$ 241$ & $\$ 222$ & $\$ 319$ & $\$ 316$ & $\$ 241$ & $\$ 223$ \\
\hline Silver & $\$ 471$ & $\$ 464$ & $\$ 413$ & $\$ 455$ & $\$ 416$ & $\$ 417$ & $\$ 414$ & $\$ 445$ & $\$ 416$ \\
\hline Gold & $\$ 488$ & $\$ 495$ & $\$ 456$ & $\$ 536$ & $\$ 541$ & $\$ 451$ & $\$ 438$ & $\$ 413$ & $\$ 459$ \\
\hline Platinum & $\$ 540$ & $\$ 539$ & $\$ 501$ & $\$ 1194$ & $\$ 1177$ & $\$ 485$ & $\$ 465$ & $\$ 515$ & $\$ 513$ \\
\hline Average & $\$ 442$ & $\$ 440$ & $\$ 385$ & $\$ 370$ & $\$ 330$ & $\$ 397$ & $\$ 395$ & $\$ 386$ & $\$ 375$ \\
\hline \multicolumn{10}{|l|}{ Full Sorting } \\
\hline Bronze & $\$ 354$ & $\$ 361$ & $\$ 305$ & $\$ 241$ & $\$ 222$ & $\$ 319$ & $\$ 315$ & $\$ 240$ & $\$ 222$ \\
\hline Silver & $\$ 471$ & $\$ 464$ & $\$ 412$ & $\$ 454$ & $\$ 414$ & $\$ 417$ & $\$ 413$ & $\$ 443$ & $\$ 414$ \\
\hline Gold & $\$ 488$ & $\$ 494$ & $\$ 455$ & $\$ 536$ & $\$ 539$ & $\$ 451$ & $\$ 437$ & $\$ 412$ & $\$ 458$ \\
\hline Platinum & $\$ 540$ & $\$ 538$ & $\$ 500$ & $\$ 1194$ & $\$ 1171$ & $\$ 485$ & $\$ 463$ & $\$ 514$ & $\$ 511$ \\
\hline Average & $\$ 442$ & $\$ 440$ & $\$ 384$ & $\$ 369$ & $\$ 329$ & $\$ 397$ & $\$ 394$ & $\$ 384$ & $\$ 373$ \\
\hline
\end{tabular}

Notes: Table summarizes weighted average premiums using four different sets of markets shares: (1) market shares under the base case/ACA (panel 1); (2) market shares that allow consumers to choose a new plan in the same metal tier as they chose in the base case; (3) market shares that allow consumers to choose any new plan, but not forgo insurance; and (4) market shares that allow consumers to choose a new plan or forgo insurance (panel 4). The premiums in the bottom panel are the same as the premiums in Table A2. 
Table A6: Impact of Subsidy Design and Churn: Premiums, Coverage, and Claims

\begin{tabular}{|c|c|c|c|c|c|c|}
\hline & Base & $(2)$ & $(9)$ & $(10)$ & $(11)$ & $(12)$ \\
\hline \multicolumn{7}{|c|}{ Scenario Definitions } \\
\hline Inertia & $\checkmark$ & & $\checkmark$ & & $\checkmark$ & \\
\hline Oligopoly & $\checkmark$ & $\checkmark$ & $\checkmark$ & $\checkmark$ & $\checkmark$ & $\checkmark$ \\
\hline Risk adjustment & $\checkmark$ & $\checkmark$ & $\checkmark$ & $\checkmark$ & $\checkmark$ & $\checkmark$ \\
\hline Endog. Subsidy & $\checkmark$ & $\checkmark$ & & & $\checkmark$ & $\checkmark$ \\
\hline Churn & $\checkmark$ & $\checkmark$ & $\checkmark$ & $\checkmark$ & & \\
\hline \multicolumn{7}{|c|}{ Monthly Premiums (Unsubsidized Unless Otherwise Indicated) } \\
\hline Bronze & $\$ 354$ & $\$ 305$ & $\$ 355$ & $\$ 311$ & $\$ 365$ & $\$ 298$ \\
\hline Silver & $\$ 471$ & $\$ 412$ & $\$ 467$ & $\$ 422$ & $\$ 480$ & $\$ 404$ \\
\hline Gold & $\$ 488$ & $\$ 455$ & $\$ 488$ & $\$ 464$ & $\$ 491$ & $\$ 445$ \\
\hline Platinum & $\$ 540$ & $\$ 500$ & $\$ 541$ & $\$ 508$ & $\$ 542$ & $\$ 490$ \\
\hline Anthem & $\$ 483$ & $\$ 405$ & $\$ 482$ & $\$ 433$ & $\$ 489$ & $\$ 395$ \\
\hline Blue Shield & $\$ 473$ & $\$ 419$ & $\$ 470$ & $\$ 430$ & $\$ 480$ & $\$ 412$ \\
\hline Health Net & $\$ 404$ & $\$ 347$ & $\$ 399$ & $\$ 362$ & $\$ 413$ & $\$ 339$ \\
\hline Kaiser & $\$ 446$ & $\$ 391$ & $\$ 445$ & $\$ 413$ & $\$ 457$ & $\$ 381$ \\
\hline Other Insurer & $\$ 388$ & $\$ 345$ & $\$ 387$ & $\$ 360$ & $\$ 398$ & $\$ 337$ \\
\hline HMO & $\$ 422$ & $\$ 369$ & $\$ 420$ & $\$ 387$ & $\$ 432$ & $\$ 361$ \\
\hline PPO & $\$ 473$ & $\$ 406$ & $\$ 471$ & $\$ 424$ & $\$ 479$ & $\$ 397$ \\
\hline Average & $\$ 442$ & $\$ 384$ & $\$ 440$ & $\$ 402$ & $\$ 451$ & $\$ 375$ \\
\hline Subsidized Avg. & $\$ 128$ & $\$ 117$ & $\$ 127$ & $\$ 94$ & $\$ 131$ & $\$ 119$ \\
\hline \multicolumn{7}{|l|}{ Coverage } \\
\hline Total Coverage & $1,756,594$ & $1,702,317$ & $1,757,423$ & $1,734,081$ & $2,509,559$ & $2,397,142$ \\
\hline$\%$ Enrolled & $74.3 \%$ & $72.0 \%$ & $74.4 \%$ & $73.4 \%$ & $75.4 \%$ & $72.0 \%$ \\
\hline Bronze & $27.1 \%$ & $29.9 \%$ & $26.7 \%$ & $23.0 \%$ & $27.7 \%$ & $30.5 \%$ \\
\hline Silver & $62.6 \%$ & $61.6 \%$ & $63.2 \%$ & $67.0 \%$ & $61.0 \%$ & $61.2 \%$ \\
\hline Gold & $6.3 \%$ & $5.7 \%$ & $6.2 \%$ & $6.9 \%$ & $7.0 \%$ & $5.6 \%$ \\
\hline Platinum & $4.0 \%$ & $2.7 \%$ & $3.9 \%$ & $3.1 \%$ & $4.3 \%$ & $2.7 \%$ \\
\hline$\%$ Switching & $0.0 \%$ & $28.4 \%$ & $0.9 \%$ & $29.8 \%$ & $2.4 \%$ & $38.7 \%$ \\
\hline \multicolumn{7}{|l|}{ Monthly Claims } \\
\hline Bronze & $\$ 224$ & $\$ 220$ & $\$ 225$ & $\$ 221$ & $\$ 329$ & $\$ 302$ \\
\hline Silver & $\$ 393$ & $\$ 389$ & $\$ 392$ & $\$ 391$ & $\$ 397$ & $\$ 377$ \\
\hline Gold & $\$ 523$ & $\$ 515$ & $\$ 524$ & $\$ 510$ & $\$ 476$ & $\$ 445$ \\
\hline Platinum & $\$ 751$ & $\$ 732$ & $\$ 753$ & $\$ 720$ & $\$ 579$ & $\$ 533$ \\
\hline Average & $\$ 370$ & $\$ 355$ & $\$ 369$ & $\$ 371$ & $\$ 392$ & $\$ 362$ \\
\hline
\end{tabular}

Notes: Table reports the impact on premiums, coverage, and claims for each scenario. Scenarios Base and (2) are the same as in Table A2. In scenarios (9) and (10), we simulate eliminating inertia and converting the ACA's endogenous subsidy to an exogenous subsidy. In scenarios (11) and (12), we simulate eliminating inertia and churn. The first panel defines each of the scenarios. The second panel summarizes enrollee-weighted average unsubsidized premiums by metal level, insurer, and plan network type. The bottom two rows of the second panel show overall enrollee-weighted average premiums ("Average") and subsidized average premiums ("Subsidized Avg."). The third panel shows total enrollment, the percentage of consumers enrolled in coverage, and market shares by metal level. The final row of the third panel indicates the percentage of consumers who switched plans from the Base scenario. The fourth panel reports average claims by metal tier and on average across all enrollees. 
Table A7: Impact of Subsidy Design and Churn: Change in Annual Per-Capita Social Welfare

\begin{tabular}{lcccccc}
\hline & Base & $(2)$ & $(9)$ & $(10)$ & $(11)$ & $(12)$ \\
\hline Scenario Definitions & & & & & & \\
Inertia & $\checkmark$ & & $\checkmark$ & & $\checkmark$ & \\
Oligopoly & $\checkmark$ & $\checkmark$ & $\checkmark$ & $\checkmark$ & $\checkmark$ & $\checkmark$ \\
Risk adjustment & $\checkmark$ & $\checkmark$ & $\checkmark$ & $\checkmark$ & $\checkmark$ & $\checkmark$ \\
$\begin{array}{l}\text { Endog. Subsidy } \\
\text { Churn }\end{array}$ & $\checkmark$ & $\checkmark$ & & & $\checkmark$ & $\checkmark$ \\
\hline $\begin{array}{l}\text { Welfare Changes } \\
\text { Cons. Surplus }\end{array}$ & $\checkmark$ & $\checkmark$ & $\checkmark$ & $\checkmark$ & & \\
$\begin{array}{l}\text { Profit } \\
\text { Gov. Spending }\end{array}$ & $\$ 488$ & $\$ 4$ & $\$ 674$ & $(\$ 105)$ & $\$ 325$ \\
$\quad$ & $(\$ 221)$ & $(\$ 10)$ & $(\$ 222)$ & $\$ 71$ & $(\$ 235)$ \\
$\quad$ Prem. Subsidies & & $(\$ 500)$ & $(\$ 8)$ & $(\$ 95)$ & $\$ 83$ & $(\$ 589)$ \\
$\quad$ Penalties & $(\$ 14)$ & $\$ 2$ & $\$ 12$ & $(\$ 10)$ & $(\$ 22)$ \\
$\quad$ Uncomp. Care & & $\$ 23$ & $(\$ 0)$ & $\$ 10$ & $(\$ 9)$ & $\$ 24$ \\
Social Welfare & & $\$ 49$ & $(\$ 1)$ & $\$ 22$ & $(\$ 21)$ & $\$ 48$ \\
\end{tabular}

Notes: Table reports the change in annual per-capita social welfare for each scenario relative to the Base (or ACA) scenario. Scenarios Base and (2) are the same as in Table A2. In scenarios (9) and (10), we simulate eliminating inertia and converting the ACA's endogenous subsidy to an exogenous subsidy. In scenarios (11) and (12), we simulate eliminating inertia and churn. The first panel defines each of the scenarios. The second panel reports the change in monthly per-capita consumer surplus, firm profit, government spending (including premium subsidies, cost sharing reductions, individual mandate penalties, and uncompensated care), and total social welfare relative to the Base scenario. 
Table A8: Sensitivity to Provider Networks: Demand Parameters

\begin{tabular}{lcccc}
\hline \hline & $(1)$ & $(2)$ & $(3)$ & $(4)$ \\
\hline Monthly Premium $(\$ 100)$ & $-0.134^{* * *}$ & $-0.135^{* * *}$ & $-0.134^{* * *}$ & $-0.135^{* * *}$ \\
& $(0.002)$ & $(0.002)$ & $(0.002)$ & $(0.002)$ \\
AV & $0.813^{* * *}$ & $0.814^{* * *}$ & $0.813^{* * *}$ & $0.813^{* * *}$ \\
& $(0.010)$ & $(0.010)$ & $(0.010)$ & $(0.010)$ \\
Silver & $0.131^{* * *}$ & $0.131^{* * *}$ & $0.131^{* * *}$ & $0.131^{* * *}$ \\
& $(0.002)$ & $(0.002)$ & $(0.002)$ & $(0.002)$ \\
HMO & $-0.036^{* * *}$ & $-0.036^{* * *}$ & $-0.036^{* * *}$ & $-0.036^{* * *}$ \\
& $(0.001)$ & $(0.001)$ & $(0.001)$ & $(0.001)$ \\
Previous Choice & $0.226^{* * *}$ & $0.219^{* * *}$ & $0.243^{* * *}$ & $0.237^{* * *}$ \\
& $(0.010)$ & $(0.010)$ & $(0.010)$ & $(0.010)$ \\
Network Breadth & & $0.000^{* * *}$ & & $0.000^{* * *}$ \\
& & $(0.000)$ & & $(0.000)$ \\
Network Inclusivity & & & $-0.076^{* * *}$ & $-0.076^{* * *}$ \\
& & & $(0.009)$ & $(0.009)$ \\
\hline
\end{tabular}

Notes: Robust standard errors are in parentheses $\left({ }^{* * *}\right.$ indicates statistical significance at the $1 \%$ level, ${ }^{* *}$ at the $5 \%$ level, and * at the $10 \%$ level). Table shows how interacting the previous choice variable with network breadth and network inclusivity affects the demand parameter estimates. Network breadth and network inclusivity are missing for approximately $20 \%$ of household-plan combinations. 
Table A9: Sensitivity to Provider Networks: Simulation Results

\begin{tabular}{|c|c|c|c|}
\hline & Base* & Eliminate Inertia & $\begin{array}{c}\text { Eliminate Inertia } \\
\text { Except Network } \\
\text { Attachment }\end{array}$ \\
\hline \multicolumn{4}{|l|}{ Monthly Premiums } \\
\hline Bronze & $\$ 355$ & $\$ 305$ & $\$ 305$ \\
\hline Silver & $\$ 451$ & $\$ 398$ & $\$ 398$ \\
\hline Gold & $\$ 475$ & $\$ 449$ & $\$ 449$ \\
\hline Platinum & $\$ 525$ & $\$ 499$ & $\$ 499$ \\
\hline Anthem & $\$ 449$ & $\$ 370$ & $\$ 369$ \\
\hline Blue Shield & $\$ 466$ & $\$ 413$ & $\$ 413$ \\
\hline Health Net & $\$ 394$ & $\$ 335$ & $\$ 335$ \\
\hline Kaiser & $\$ 436$ & $\$ 383$ & $\$ 383$ \\
\hline Other Insurer & $\$ 367$ & $\$ 339$ & $\$ 339$ \\
\hline HMO & $\$ 407$ & $\$ 361$ & $\$ 362$ \\
\hline PPO & $\$ 464$ & $\$ 395$ & $\$ 394$ \\
\hline Average & $\$ 430$ & $\$ 375$ & $\$ 375$ \\
\hline Subsidized Avg. & $\$ 135$ & $\$ 123$ & $\$ 123$ \\
\hline \multicolumn{4}{|l|}{ Coverage } \\
\hline Total Coverage & $1,712,503$ & $1,659,073$ & $1,658,788$ \\
\hline$\%$ Enrolled & $74.4 \%$ & $72.1 \%$ & $72.1 \%$ \\
\hline Bronze & $26.3 \%$ & $29.2 \%$ & $29.3 \%$ \\
\hline Silver & $64.0 \%$ & $64.0 \%$ & $63.8 \%$ \\
\hline Gold & $5.8 \%$ & $4.7 \%$ & $4.7 \%$ \\
\hline Platinum & $3.9 \%$ & $2.2 \%$ & $2.2 \%$ \\
\hline$\%$ Switching & $0.0 \%$ & $24.8 \%$ & $25.2 \%$ \\
\hline \multicolumn{4}{|c|}{ Monthly Average Claims } \\
\hline Bronze & $\$ 232$ & $\$ 225$ & $\$ 225$ \\
\hline Silver & $\$ 391$ & $\$ 391$ & $\$ 391$ \\
\hline Gold & $\$ 522$ & $\$ 525$ & $\$ 525$ \\
\hline Platinum & $\$ 737$ & $\$ 762$ & $\$ 761$ \\
\hline Average & $\$ 371$ & $\$ 357$ & $\$ 356$ \\
\hline \multicolumn{4}{|c|}{ Annual Welfare Changes } \\
\hline Cons. Surplus & & $\$ 510$ & $\$ 510$ \\
\hline Profit & & $(\$ 213)$ & $(\$ 213)$ \\
\hline \multicolumn{4}{|l|}{ Gov. Spending } \\
\hline Prem. Subsidies & & $(\$ 456)$ & $(\$ 457)$ \\
\hline CSRs & & $(\$ 9)$ & $(\$ 10)$ \\
\hline Penalties & & $\$ 24$ & $\$ 24$ \\
\hline Uncomp. Care & & $\$ 49$ & $\$ 50$ \\
\hline Social Welfare & & $\$ 868$ & $\$ 871$ \\
\hline
\end{tabular}

Notes: Table reports the impact of inertia and provider networks on monthly premiums, coverage, monthly average claims, and annual per-capita welfare. These simulations were run on a subset of the data because provider network data are missing for some plans. Scenario Base* reports the observed data for the non-missing plans. The first counterfactual scenario reports the complete elimination of inertia, based on demand estimation with network inclusivity. The second counterfactual scenario reports the elimination of inertia except the portion linked to network inclusivity. 